\title{
DEMOGRAPHICS AND FDI: LESSONS FROM CHINA'S ONE-CHILD POLICY
}

\author{
John B. Donaldson \\ Christos Koulovatianos \\ Jian Li \\ Rajnish Mehra \\ Working Paper 24256 \\ http://www.nber.org/papers/w24256 \\ NATIONAL BUREAU OF ECONOMIC RESEARCH \\ 1050 Massachusetts Avenue \\ Cambridge, MA 02138 \\ January 2018, Revised May 2021
}

We thank Costas Arkolakis, Costas Azariadis, Espen Henriksen, Dilip Mookherjee, Robert Lucas, Julien Penasse, Edward Prescott, Laszlo Sandor, Gustavo Ventura and participants of the Econometric Society meetings in Cotonou for helpful comments. We are especially grateful to Thomas Cooley for detailed feedback and suggestions. The views expressed herein are those of the authors and do not necessarily reflect the views of the National Bureau of Economic Research.

NBER working papers are circulated for discussion and comment purposes. They have not been peer-reviewed or been subject to the review by the NBER Board of Directors that accompanies official NBER publications.

(C) 2018 by John B. Donaldson, Christos Koulovatianos, Jian Li, and Rajnish Mehra. All rights reserved. Short sections of text, not to exceed two paragraphs, may be quoted without explicit permission provided that full credit, including $\odot$ notice, is given to the source. 
Demographics and FDI: Lessons from China's One-Child Policy

John B. Donaldson, Christos Koulovatianos, Jian Li, and Rajnish Mehra

NBER Working Paper No. 24256

January 2018, Revised May 2021

JEL No. E13,F11,F12,J11,O11

\section{$\underline{\text { ABSTRACT }}$}

Following the introduction of the one-child policy in China, the capital-labor ratio of China increased relative to that of India, while FDI/GDP inflows to China vs India simultaneously declined. These observations are explained in the context of a simple neoclassical OLG paradigm. The adjustment mechanism works as follows: the reduction in the growth rate of the (urban) labor force due to the one-child policy increases the capital per worker inherited from the previous generation. The resulting increase in China's domestic capital - labor ratio thus 'crowds out' the need for FDI in China relative to India. Our paper is a contribution to the nascent literature exploring demographic transitions and their effects on FDI flows.

John B. Donaldson

Columbia Business School

3022 Broadway, Uris Hall

New York, NY 10027

jd34@gsb.columbia.edu

Christos Koulovatianos

Department of Economics

University of Luxembourg

$162 \mathrm{~A}$ avenue de la Faïencerie

Campus Limpertsberg, BRC 1.06E

L-1511

Luxembourg

christos.koulovatianos@uni.lu
Jian Li

Université du Luxembourg

Campus Limpertsberg,

162 A, avenue de la Faïencerie

L-1511 Luxembourg

Campus Office : BRC 0.02

jian.li@uni.lu

Rajnish Mehra

Department of Economics

W. P. Carey School of Business

Arizona State University

PO Box 879801

Tempe, AZ 85287-9801

and NBER

rajnish.mehra@asu.edu 


\section{Introduction}

A central tenet of neoclassical growth theory asserts that the marginal product of capital declines as the capital-labor $(\mathrm{K} / \mathrm{L})$ ratio increases. This led Lucas (1990) to ask the question: "Why doesn't capital flow from developed to developing countries?" - the implicit assumption being that developed and developing countries are characterized by high $(\mathrm{K} / \mathrm{L})$, low capital return and low $(\mathrm{K} / \mathrm{L})$, high capital return regimes, respectively. In this paper we investigate how these capital flows are affected by diverging demographic trends in the capital receiving countries, most especially if one of the countries is experiencing population decline.

The mechanism we highlight is as follows: as population declines in a country, the capital stock of each older cohort accrues to a significantly smaller number of young workers, resulting in an endogenous increase in the capital per worker. Accordingly, capital returns are lower than in an otherwise identical country not suffering from population decline, with the result that relative capital flows into that country (FDI-foreign direct investment), ceteris paribus, also decline.

As the empirical counterpart to this scenario, we examine the evolution of both the K/L ratio and foreign direct investment (FDI) following the 1982 introduction of the one-child policy in China and contrast it with India, which introduced an unsuccessful two-child policy of its own. Our choice of using India as the 'control' country is motivated by the fact that except for differences in their growth rates of labor, both India and China are similarly matched across most major macroeconomic aggregates, most critically output and total factor productivity.

China's strictly enforced policy intervention led to a decline in its working-age population. Over the same period (post 1982), China's K/L ratio increased considerably relative to India's, while its relative FDI intensity (FDI/GDP) declined. Both observations will be seen to follow from the mechanism introduced above. To illustrate this mechanism, we construct a parsimonious two-country and the 'Rest of the World' OLG model that is consistent with these observations. Our results are dependent on two key assumptions:

a. Home bias in financing investments in both countries: investments are financed using domestically generated savings with FDI covering any shortfall, a typical pattern in many emerging market economies. 
b. Household savings rates are undiminished by reduced fertility: indeed, the literature identifies an enormous increase in China's savings rate following the one-child policy implementation ${ }^{1}$.

Complementary to the mechanism studied in this paper, an increase in the propensity to save may impact relative FDI flows, and may overwhelm the demographic mechanism. Accordingly, we examine two model modifications that lead to increased savings: an increase in life expectancy and a greater proclivity to leave bequests (or bequests of larger magnitude) ${ }^{2}$. We show that for reasonable parameterizations demographic effects dominate these modifications.

An outline of the paper is as follows. Section 2 documents the relative population dynamics and FDI flows for India and China post China's implementation of its one-child policy. In Section 3 we present a parsimonious OLG international investment model, which is able to replicate the patterns found in the data. Section 4 examines the implications of the model. Section 5 extends the basic model to allow for an increase in savings, while Section 6 concludes.

\section{Comparative Population Policies and Macroeconomic Dynamics in China and India: Data}

\subsection{Comparative population policies and dynamics}

Both China and India initiated public policies to control population growth. India's two-child policy was voluntary and ineffective. In contrast, China's one-child policy was mandatory and highly effective. Figure 1 illustrates this major exogenous demographic policy intervention. It depicts various population growth scenarios for both countries with confidence intervals obtained through Bayesian averaging ${ }^{3}$.

\footnotetext{
${ }^{1}$ Various papers offer different explanations for this savings increase, all of a social nature. See Appendix A for a full discussion.

${ }^{2}$ Empirically, the increase in life expectancy in India and China during the period under study was essentially the same. Furthermore, there is little evidence that the bequest motive is a dominant social force, particularly in China (see Horioka (2014)). These observations suggest that neither phenomenon has been a significant determinant of relative FDI flows in China vs India.

${ }^{3}$ Both data and population projection scenarios portrayed in Figure 1 are obtained from the United Nations Population division. Computations are done using an open-source package described in Raftery et al. (2012) and Gerland et al. (2014).
} 
China: Population (Age 15-59)

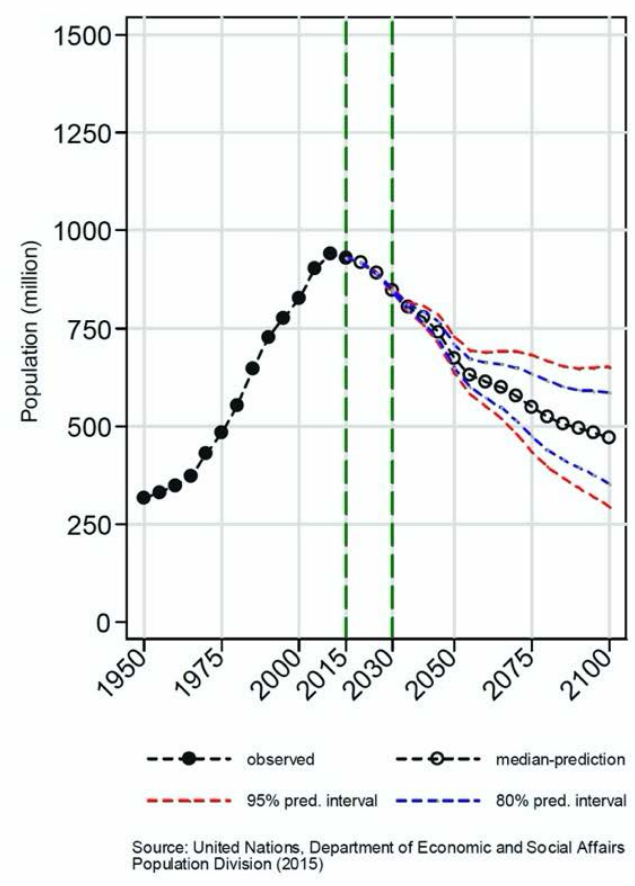

India: Population (Age 15-59)

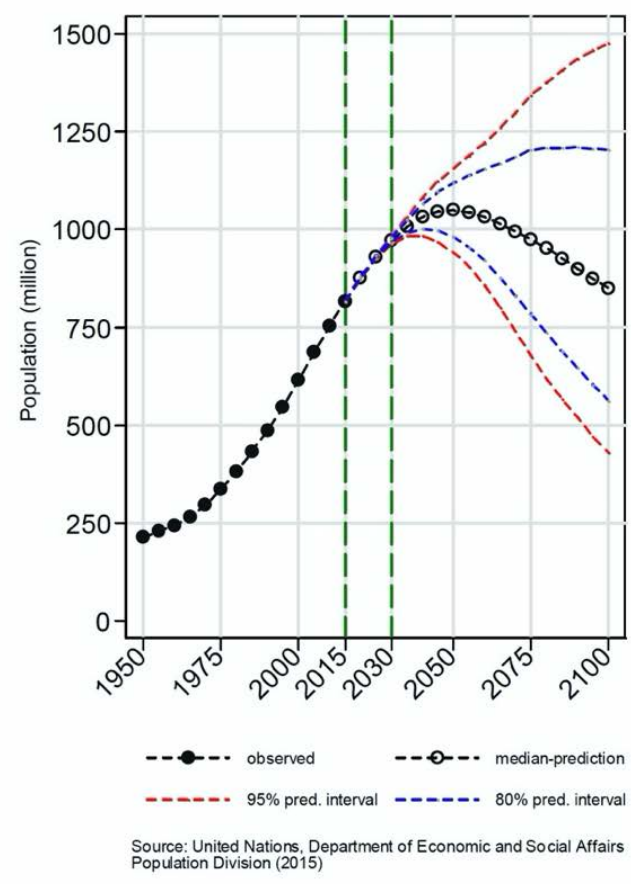

Figure 1 - Working-age population dynamics in China and India. The two vertical dashed lines indicate that, until 2030, the assumed working population dynamics are robust to any realistic population-growth scenario.

Three key observations result from Figure 1:

1. In China, an absolute decline in the working-age population (aged 15-59) began in 2010 and will continue under all reasonable scenarios.

2. With a high degree of confidence, the working-age population of India is projected to continue increasing at least until 2030.

3. After 2025, the working-age population of India is projected to exceed that of China under all realistic scenarios.

The increase in China's working-age population for roughly 18 years following the one-child policy implementation reflects the delayed reaction due to schooling and other work preparation activities until at least the age of $16^{4}$. Figure 1 clearly demonstrates that, in contrast to India, China's policy intervention was not only effective shortly after

\footnotetext{
${ }^{4}$ This delayed reaction is also due to a gradual increase in policy effectiveness and the gradual elimination of rural exemptions. The model to be proposed captures this decline as occurring in a single 25-year period, which is an artifact of the model's parsimony and the choice of a time interval equivalent to 25 years.
} 
implementation, but also that its effects on population dynamics are expected to persist beyond one generation ${ }^{5}$. The anticipation of these policy effects and their persistence is crucial for investment decisions because investors are forward-looking and major investments are typically long-lived.

\subsection{Comparative Macroeconomic Performance}

Table 1 presents comparative productivity and GDP growth rates. These were similar in China and India before and, significantly more so, after the exogenous demographic intervention, which allows us to plausibly attribute trend differences between China and India (e.g., relative FDI flows) principally to China's actions.

\section{Growth Rates of Macro Aggregates.}

Annual rates (\%)

\begin{tabular}{|c|c|c|c|c|c|c|c|c|}
\hline & \multicolumn{2}{|c|}{$g_{L}$} & \multicolumn{2}{c|}{$g_{K}$} & \multicolumn{2}{c|}{$g_{Y}$} & \multicolumn{2}{c|}{$g_{A}$} \\
& growth rate of labor & growth rate of capital & growth rate of GDP & \multicolumn{2}{c|}{ labor productivity growth } \\
\hline & China & India & China & India & China & India & China & India \\
\hline $\begin{array}{c}\text { Period 1 } \\
1960-1981\end{array}$ & 2.05 & 2.27 & 7.89 & 3.52 & 5.11 & 4.14 & 1.69 & 2.17 \\
\hline $\begin{array}{c}\text { Period 2 } \\
1982-2014\end{array}$ & 0.82 & 1.99 & 13.97 & 12.42 & 9.14 & 9.28 & 5.94 & 5.74 \\
\hline
\end{tabular}

Table 1

Source: Penn World Tables and United Nations. Data from the 1960s and 1970s is presented for comparison purposes only. Both China and India instituted market economy reforms in 1992. Our comparative model, to be detailed in Sections 3 and 4, thus provides insights only for the post - 1992 period.

Both China and India experienced similar rapid real GDP growth in the post implementation (1982-2014) period (see the two columns under $g_{Y}$ in Table 1$)^{6}$. Note

\footnotetext{
${ }^{5}$ The recently introduced (2017) two-child policy in China may alter the anticipated population dynamics in China, depicted in the left panel of Figure 1, after 2030. Nevertheless, population dynamics 15 years ahead will not be affected: see the time interval bracketed by the vertical dashed lines. As of January 2020, there has been no uptick in Chinese fertility. See also Zhao (2017).

${ }^{6}$ For the calculations in Table 1 and the subsequent theoretical analysis, we employ a Cobb-Douglas production function given by $Y_{t}=K_{t}^{\alpha}\left(A_{t} L_{t}\right)^{1-\alpha}$, where $Y$ is GDP, $K$ is capital, $L$ is labor, and $A$ is labor productivity ( $K$ is measured as the value of the capital stock and $L$ as total hours worked). The two columns of Table 1 under " $g_{A}$ ", labor productivity growth, have been calculated using the formula $g_{A}=$
} 
Period 1, and more so in Period 2 while increasing in both ${ }^{7}$. Real capital stock grew slightly more rapidly in China in the latter period, while the dramatic labor force growth slowdown in China is clearly evident in the $g_{L}$ column where L denotes aggregate hours worked.

We define $\Delta g_{x, t}=g_{x, C, t}-g_{x, I, t}$ as the growth rate differential between China and India for variable x. Figure 2 plots $\Delta g_{L, t}$ and $\Delta g_{K, t}$, prior and post 1982, when the onechild policy was first implemented. Solid lines are the Hodrick-Prescott filtered series (using a smoothing parameter $\lambda=6.25$ ). Shortly thereafter, $\Delta g_{L, t}$ assumes negative values which persist (right axis in Figure 2), capturing the long-term impact of the strictly enforced policy directive in China. A key feature of Figure 2 is the simultaneous reversal of the $\Delta g_{L, t}$ and $\Delta g_{K, t}$ trajectories, suggesting a causal link between the demographic intervention and the differential capital-accumulation dynamics in the two countries post 1982.

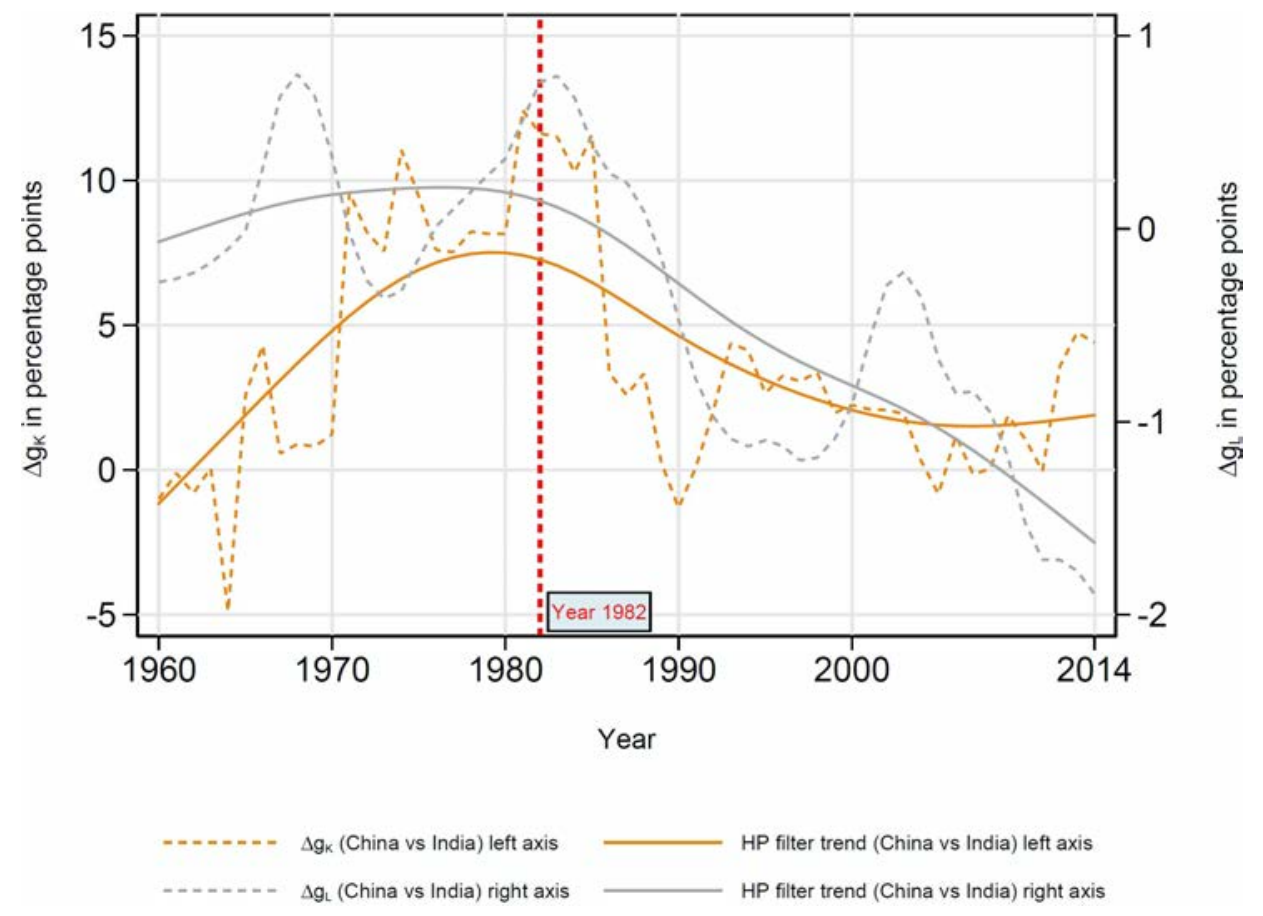

Figure 2 - Differential growth rates of capital and labor: China vs India.

$\left(g_{Y}-\alpha g_{K}\right) /(1-\alpha)-g_{L}$, where we have assumed that the capital intensity parameter, $\alpha=1 / 3$ for both China and India.

${ }^{7}$ The similarities in productivity differences between China and India are also supported by Hsieh and Klenow (2009), and Bollard, Klenow and Sharma (2013). 
As Table 1 indicates, $\Delta g_{A}$ rose from $-0.48 \%$ pre 1982 to $0.20 \%$ in the 1982 2014 period. This increase was, however, not strong enough to compensate for the impact of differential population growth on capital growth: $\Delta g_{K, t}$ while positive, is in general decline after 1982 .

\subsection{Comparative K/L and FDI dynamics}

Figure 3 presents the post 1982 - time path of $\log \left((\mathrm{FDI} / \mathrm{GDP})_{\text {China }} /(\mathrm{FDI} / \mathrm{GDP})_{\text {India }}\right)$ and $\log \left((\mathrm{K} / \mathrm{L})_{\text {China }} /(\mathrm{K} / \mathrm{L})_{\text {India }}\right)^{8}$. It highlights two insights. First, the growth in China's K/L ratio outpaced India's following the 1982 policy intervention. Second, during the same period, FDI intensity (FDI as a share of GDP) grew faster in India than in China. In 1990, China's FDI/GDP ratio was about 30 times larger than India, but by 2014, it had declined to less than twice ${ }^{9}$.

In what follows, we propose a neoclassical model to illustrate these empirical observations.

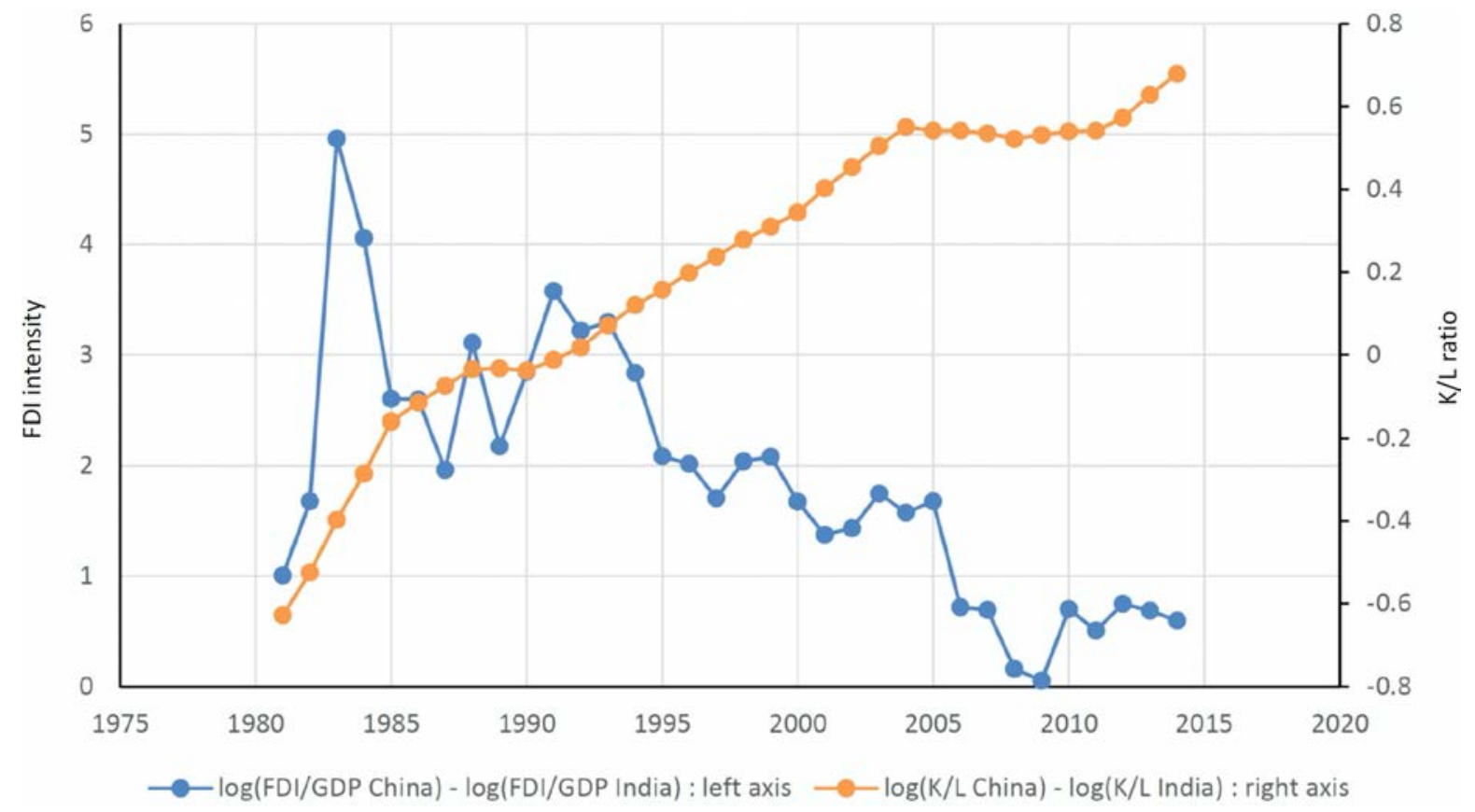

Figure 3 - Differential growth rates of FDI/GDP and K/L: China vs India.

\footnotetext{
${ }^{8}$ The data underlying Figure 3 is found in Table A.1 of Appendix E, available online.

${ }^{9}$ In Appendix E we document the data used in Figure 3 and offer a robustness check focusing on K/L trends of the non-agricultural workforce in both countries (see Figure A.6 and Table A.2 in Appendix E). It is important to note that FDI in China and India during the period examined did not represent the purchase of existing domestic capital by foreign entities; observed FDI data predominantly describes the formation of new capital. This experience contrasts with that of the US where the vast majority of FDI is for the purchase of claims to already existing capital stock.
} 


\section{The Modeling Environment}

We imagine two developing economies each initially closed to international capital markets, and each with low capital stock levels and low capital/labor ratios. With abundant labor and relatively scarce capital, the marginal product of capital in each country substantially exceeds the corresponding 'world interest rate'. As a result, when both countries allow foreign direct investment (FDI), capital flows in from the developed world to equalize the domestic marginal product of capital to the 'world interest rate'. This determines the initial level of FDI in each country. Both countries benefit by supplementing domestic capital with FDI, as a large share (approximately two-thirds) of the additional output resulting from the increased capital stock accrues to the working population as wage payments.

In one of the two countries, exogenous fertility restrictions (China's effective onechild policy) lead to negative population growth which, after a lag, creates a negative workforce growth. It is in this environment that the mechanism of this paper becomes theoretically and empirically active, and our objective is to study its consequences for relative FDI inflows into the two countries. We accomplish our study first in the context of a parsimonious model, and then show that its conclusions are robust to important generalizations.

\subsection{The Model}

We construct a parsimonious, perfect-foresight OLG model of two countries, 1 and 2 , that receive FDI capital from the rest of the world (ROW). Both countries are price takers in international capital markets, where the 'world interest rate', $\mathrm{r}^{*}$, is constant. Key simplifying assumptions, none of which are crucial to the model's implications, are:

- Capital flows from ROW to countries 1 and 2, but no capital flows between countries 1 and $2^{10}$.

- The labor force of each country cannot move to the other country, but factor

\footnotetext{
${ }^{10}$ China and India have historically faced both geographical and political barriers to capital flows and trade. Indeed, as late as 2018, China was not one of the top-10 originators of FDI into India and similarly, for Indian FDI into China. See, for example, Statista 2020 using the term "actually utilized value of foreign direct investment in China by countries and regions". The reported figures are for both physical FDI and the purchase of claims to existing capital.
} 
flows within a country are frictionless ${ }^{11}$.

- There is no international trade in final goods between the two countries ${ }^{12}$.

\subsection{Production}

Aggregate domestic production in country $i \in\{1,2\}$ in period $t$ is characterized by the production technology, ${ }^{13}$

$$
\bar{Y}_{i, t}=Y_{i, t}+Y_{i, t}^{r}
$$

where,

$$
Y_{i, t}=\left(K_{i, t}\right)^{\alpha_{i}}\left(\bar{A}_{i, t} L_{i, t}\right)^{1-\alpha_{i}}, \quad \alpha_{i} \in(0,1)
$$

and

$$
Y_{i, t}^{r}=\left(F D I_{i, t}\right)^{\alpha_{i}}\left(\bar{A}_{i, t} L_{i, t}^{r}\right)^{1-\alpha_{i}}
$$

Superscript " $r$ " denotes capital from the ROW, while the location of production is country $i$. Specifically, $K_{i, t}$ is the period $t$ capital of country $i$ invested by domestic firms, while $F D I_{i, t}$ is the stock of FDI capital invested by ROW firms in country $i . L_{i, t}$ is the workforce of country $i$ working in firms using capital financed by country $i$, while $L_{i, t}^{r}$ denotes workers in country $i$ that work for ROW companies using FDI. Variables with a bar denote country aggregates (see, for example $\bar{Y}_{i, t}$ in equation (1). The common depreciation rate for capital $K_{i, t}$ and $F D I_{i, t}$ is $\delta \in(0,1]$, for $i \in\{1,2\}$, while $\bar{A}_{i, t}$ is the period- $t$ level of labor productivity, common to both sectors in country $i{ }^{14}$ In each country, we postulate a large number of identical firms operating the technologies

\footnotetext{
${ }^{11}$ Although the labor-input data behind Table 1 is measured in aggregate hours, we assume fixed hours per worker and normalize hours in terms of full-time equivalent workers.

${ }^{12}$ This is a simplifying assumption, following Backus, Kehoe, and Kydland (1992) and Holmes, McGrattan and Prescott (2015). While there are plausible reasons to assume that FDI may be more focused on selling in a local market rather than as a base for exports (see the discussion in Holmes, McGrattan and Prescott, 2015, p. 1159), this assumption is not critical for the qualitative conclusions implied by the model. Assuming a fully integrated final-goods market would add more arbitrage conditions but would not eliminate the key mechanisms behind the K/L ratio dynamics studied here.

${ }^{13}$ Our production structure is a simplified version of the one in McGrattan and Prescott $(2009,2010)$ and Holmes et al. (2015).

${ }^{14}$ While labor productivity may be firm-specific, we lack any data on productivity growth in foreignowned vs domestically-owned firms in either China or India; hence the simplifying assumption. Assuming $A_{i, t} \neq A_{i, t}^{r}$ leads to the same conclusions as the present formulation.
} 
described by equations (2) and (3). Aggregation is achieved in the sense described in Proposition 3.1.

\section{Proposition 3.1:}

Under assumptions (2) and (3) output in country $i \in\{1,2\}$ is given by,

$$
\bar{Y}_{i, t}=\bar{K}_{i, t}^{\alpha_{i}}\left(\bar{A}_{i, t} \bar{L}_{i, t}\right)^{1-\alpha_{i}}=\left(K_{i, t}+F D I_{i, t}\right)^{\alpha_{i}}\left(\bar{A}_{i, t} \bar{L}_{i, t}\right)^{1-\alpha_{i}}
$$

Proof: See online Appendix B.

Based on the assumption of no cross-country labor force mobility, and assuming full employment in each country,

$$
\bar{L}_{i, t}=L_{i, t}+L_{i, t}^{r}
$$

where $\bar{L}_{i, t}$ is the total workforce (population) in country $i \in\{1,2\}$. We maintain our assumption that population growth and productivity growth in country $i \in\{1,2\}$ are both exogenous constant over time, i.e., ${ }^{15}$

$$
\frac{\bar{L}_{i, t+1}}{\bar{L}_{i, t}}=e^{g_{\bar{L}, i}}, \frac{\bar{A}_{i, t+1}}{\bar{A}_{i, t}}=e^{g_{\bar{A}, i}} .
$$

\subsection{Efficient factor allocation}

Profit-maximizing firms, domestic or foreign, located in country $i \in\{1,2\}$, equate marginal products to factor prices. Competitive-equilibrium factor inputs $\left(K_{i, t}, F D I_{i, t}, L_{i, t}, L_{i, t}^{r}\right)$ are efficiently allocated within each country to maximize domestic production. The intra-temporal optimality conditions for the efficient allocation of these factor inputs are,

$$
M P K_{i, t}=M P K_{i, t}^{r} \quad \text { and } \quad M P L_{i, t}=M P L_{i, t}^{r}
$$

where "MPK" and "MPL" signify the marginal products of capital and marginal product of labor, respectively.

\footnotetext{
${ }^{15}$ These growth rates need not be identical across countries as our notation allows. Indeed, the one-child policy will manifest itself as a structural change in the constant population growth rate in one country.
} 


\subsection{Households, Domestic Savings, and National Capital}

We use a simple variant of Diamond's (1965) overlapping-generations (OLG) model. All individuals live for two periods. ${ }^{16}$ When young, individuals work, consume and accumulate capital (save). When old, individuals rent their capital to firms (in which the young generation works), consume, and die. Omitting subscript $i$, unless necessary, the following notation applies:

$c_{1, t} \equiv$ consumption of a young agent born at time $t$ ( $t$ specifies the generation)

$c_{2, t} \equiv$ consumption when old at time $t+1$ of an individual born at time $t$

$\bar{L}_{t} \equiv$ number of individuals born in period $t$ and working in period $t$

$w_{t} \equiv$ competitive wage received in period $t$

$r_{t+1}^{*} \equiv$ world interest rate (cost of capital) paid on savings held from period $t$ to period $t+1$.

Aggregate consumption in period $t+1$ is thus $L_{t} \cdot c_{2, t}+L_{t+1} \cdot c_{1, t+1}$. Within each cohort, individuals are identical with utility function:

$$
U\left(c_{1, t}, c_{2, t}\right)=\log \left(c_{1, t}\right)+\beta \log \left(c_{2, t}\right), \text { where the discount factor } \beta \in(0,1) .
$$

Labor supply is inelastic and equal to one unit per period; accordingly, the period $t$ labor income of a working individual is $w_{t}$.

The consumption of generation $t$, in period $t+1$, (when old) is thus given by,

$$
c_{2, t}=\left(1+r_{t+1}^{*}\right) s_{t}
$$

where $s_{t}$ denotes period $t$ savings of a household (when young). Since the only source of income when young is wage income $w_{t}, s_{t}=w_{t}-c_{1, t}$, equation (9) becomes

$$
c_{1, t}+\frac{c_{2, t}}{1+r_{t+1}^{*}}=w_{t}
$$

\footnotetext{
${ }^{16}$ The period length is fixed in the model, an assumption that ignores changes in life expectancy which has increased in both countries over the historical period under study, somewhat more so in China. What has not changed, however, is the retirement age (60 years in China for those employed in state-run enterprises, municipal service workers (teachers) and in professions involving manual labor) and thus the length of the average post-retirement period has increased. It is the length of the latter period that is of relevance to the model's implications regarding savings behaviors, something that we capture in the model generalizations detailed in Section 4.
} 
Maximizing lifetime utility (8) subject to the lifetime constraint (10) yields, ${ }^{17}$

$$
s_{t}=\frac{\beta}{1+\beta} w_{t}
$$

Aggregate domestic savings of the young generation, $\bar{S}_{i, t}=s_{i, t} \bar{L}_{i, t}$, is equal to aggregate investment, which augments the national capital stock of the country in period $t+1$. Equation (11) then implies,

$$
K_{i, t}=(1-\delta) K_{i, t-1}+\frac{\beta_{i}}{1+\beta_{i}} w_{i, t-1} \bar{L}_{i, t-1,} \quad i \in\{1,2\}
$$

where

$$
\bar{S}_{i, t-1}=\frac{\beta_{i}}{1+\beta_{i}} w_{i, t-1} \bar{L}_{i, t-1}
$$

\subsection{Equilibrium and Steady-State Characterization}

Equilibrium is characterized by a set of prices and quantities at which firms maximize profits, households maximize utility and domestic and international markets clear.

Equation (4) yields a key implication: ${ }^{18}$

$$
r^{*}+\delta=\frac{\partial \bar{Y}_{i, t}}{\partial \bar{K}_{i, t}} \equiv \overline{M P K}_{i, t}=M P K_{i, t}=M P K_{i, t}^{r}, \quad i \in\{1,2\}
$$

which in turn provides the background to Proposition 3.2.

\section{Proposition 3.2.}

The steady state growth path for economy $i$ is characterized by the equations,

\footnotetext{
${ }^{17}$ In equation (11), the key operative feature of the model's consumer side is the constant $s_{t} / w_{t}$ ratio. In Online Appendix D, it is shown that the addition of a bequest motive and/or allowing for increased life expectancy, does not alter this specific feature, and can be shown simply to alter the fraction saved. In particular, the incorporation of these features can be shown to be isomorphic to increases in the parameter $\beta$ of equation (11). For this reason we retain the present simple formulation, as it allows the principal conclusions of the model to have precise analytical representation.

${ }^{18}$ Note that the capital return in both countries is fixed by the world interest rate $r^{*}$ plus the common depreciation rate. This is a consequence of the competitive assumption and the free flow of capital internationally. Returns, particularly in China, have historically shown wide variation, however. See Appendix A for a discussion of the related literature.
} 


$$
\begin{gathered}
\left(\frac{\bar{Y}_{i, t}}{\bar{L}_{i, t}}\right)^{S S}=\left(\frac{\alpha_{i}}{r^{*}+\delta}\right)^{\frac{\alpha_{i}}{1-\alpha_{i}}} \bar{A}_{i, t}, \\
\left(\frac{K_{i, t}}{\bar{L}_{i, t}}\right)^{S S}=\frac{\beta_{i}\left(1-\alpha_{i}\right)}{\left(1+\beta_{i}\right)\left(e^{\left.g_{\bar{A}, i}+g_{\bar{L}, i}+\delta-1\right)}\right.}\left(\frac{\alpha_{i}}{r^{*}+\delta}\right)^{\frac{\alpha_{i}}{1-\alpha_{i}}} \bar{A}_{i, t},
\end{gathered}
$$

and,

$$
\left(\frac{F D I_{i, t}}{\bar{Y}_{i, t}}\right)^{S S}=\frac{\alpha_{i}}{r^{*}+\delta}-\frac{\beta_{i}\left(1-\alpha_{i}\right)}{\left(1+\beta_{i}\right)\left(e^{\left.g_{\bar{A}, i}+g_{\bar{L}, i}+\delta-1\right)}\right.}
$$

Proof: See online Appendix C.

\subsection{Impact of the One-Child Policy on the Steady-State FDI/GDP ratio}

Based on equation (15), an exogenous demographic intervention, such as the onechild policy, that permanently reduces population growth from a constant rate $g_{L, i}$ to a lower constant rate $\hat{g}_{L, i}$, will permanently increase national capital per worker. By equation (16), the crowding out of FDI is manifested as a drop in the long run steadystate FDI/GDP ratio. ${ }^{19}$ Equations (14) - (16) will form the basis of our analysis going forward.

\subsection{Transition Dynamics: Capital Adjustment Costs}

In the absence of capital adjustment costs, optimal investment is governed by,

$$
r^{*}+\delta=\overline{M P K}_{i, t}, \quad i \in\{1,2\}
$$

With frictionless capital flows, complete per period capital depreciation and unlimited capital availability at the world cost of capital $r^{*}$, steady state transitions due to underlying parameter changes will occur in one period which, in this model, corresponds to one-half of an adult lifetime. In order to better match the empirical duration of transitions, and the gradual rise in the $\mathrm{K} / \mathrm{L}$ ratio reported in Figure 3, we impose a

\footnotetext{
${ }^{19}$ Notice that equation (15) does not refer to the ratio $\left(\bar{K}_{i, t} / \bar{L}_{i, t}\right)^{S S}$, which is not affected by changes in parameters other than $r^{*}, \delta$, and $\alpha_{i}$, as implied by equation( 13). Crowding out of FDI arises from the fact that the steady state $\left(\bar{K}_{i, t}\right)^{s s} /\left(\bar{Y}_{i, t}\right)^{s s}=\left[\left(K_{i, t}\right)^{s s}+\left(F D I_{i, t}^{r}\right)^{s s}\right] /\left(\bar{Y}_{i, t}\right)^{s s}=\alpha_{i} /\left(r^{*}+\delta\right)$, and is independent of the growth rate of labor. Accordingly, a reduction in $\left(F D I_{i, t}\right)^{S S} /\left(\bar{Y}_{i, t}\right)^{S S}$ accompanies an increase in $\left(K_{i, t}\right)^{S S} /\left(\bar{Y}_{i, t}\right)^{S S}$, amounting to the substitution of domestic capital for foreign capital.
} 
capital adjustment cost on the dynamics implied by equations (12) and (17). In particular, we modify equation (17) to be of the form:

$$
r^{*}+\delta=\overline{M P K}_{i, t}+\psi(t, \hat{t}), \quad i \in\{1,2\}
$$

where,

$$
\psi(t, \hat{t})=\left\{\begin{array}{c}
0 \quad, \quad \text { if } t \leq \hat{t} \\
\eta \cdot(1-\chi)^{t-\hat{t}-1,}, \text { if } \hat{t}+1 \leq t
\end{array},\right.
$$

where $\eta>0, \chi \in(0,1)$. The symbol $\hat{t}>0$ denotes the period in which an exogenous intervention shocks the equilibrium away from its steady-state path. For some periods after the intervention there is a loss of $\eta \cdot(1-\chi)^{t-\hat{t}-1}$ in capital returns, which we postulate as due to a combination of industrial relocation costs and institutional adjustment costs such as bureaucratic frictions ${ }^{20}$. These institutional adjustments are gradually eliminated with the capital-returns wedge, $\eta \cdot(1-\chi)^{t-\hat{t}-1}$, decaying over time at rate $\chi$. Equilibrium in country $i \in\{1,2\}$ is characterized by conditions (12) and (18), with adjustment costs inducing long-lasting transitions in the capital labor ratio. In steady state, adjustment costs are zero by construction.

In the next sections we study the effects of an exogenous demographic intervention on the equilibrium $\mathrm{K} / \mathrm{L}$ ratio and FDI, specifically one characterized by a sudden and permanent decrease in population growth in one of the two countries similar to what followed the implementation of the one-child policy in China. To analyze these effects in detail, we rely on specific relationships describing $\mathrm{K} / \mathrm{L}$ ratio dynamics that apply both along the transition path toward the steady-state growth path, and along the steady state growth path itself. These are presented below:

Equation (18) implies

$$
\frac{\bar{K}_{i, t}}{\bar{A}_{i, t} \bar{L}_{i, t}}=\left[\frac{\alpha_{i}}{r^{*}+\delta-\psi(t, \hat{t})}\right]^{\frac{1}{1-\alpha_{i}}} .
$$

\footnotetext{
${ }^{20}$ The exogenous wedge that we impose upon condition (17) through equations (18) and (19) is similar to measured wedges that reflect deviations from the covered interest rate parity condition observed by Du, Tepper, and Verdelhan (2017) after the recent financial crisis.
} 
In turn, equation (20) implies that the growth rates of capital, labor and labor productivity are jointly related as in equation (21),

$$
g_{\bar{K}, i, t} \equiv \ln \left(\bar{K}_{i, t}\right)-\ln \left(\bar{K}_{i, t-1}\right)=\frac{1}{1-\alpha_{i}} \ln \left[\frac{r^{*}+\delta-\psi(t-1, \hat{t})}{r^{*}+\delta-\psi(t, \hat{t})}\right]+g_{\bar{A}, i, t}+g_{\bar{L}, i, t} .
$$

From equation (21) we see that an exogenous demographic intervention that reduces population growth from a constant rate $g_{\bar{L}, i}$ to a lower constant rate $\hat{g}_{\bar{L}, i}$, will also cause a drop in the growth rate of domestic capital, absent changes in labor productivity growth.

Equations (16)-(21) form the backbone of the numerical analysis to follow. In the next section we replicate the empirical regularities depicted in Section 2 as equilibrium outcomes of the model just detailed when one of the countries experiences a permanent negative shock to its population growth rate.

\section{Model Implications}

We study a parametrized version of the model where an exogenous demographic intervention occurs in period 10 . The annual adjustment wedge on the world capital return is $\eta=0.5 \%$, with a rate of decay determined by $\chi=30 \% .{ }^{21}$ These parameter values imply that the adjustment wedge half-life is about 50 years, which corresponds to two generations of young workers ( $\mathrm{T}=25$ years). All other parameter values are as in Table 2 below:

\footnotetext{
${ }^{21}$ Both economies in our analysis share these common parameter values for $\eta$ and $\chi$.
} 
Assessing the Strength of Demographic vs Savings Rate Changes

Parameter Values (\%)

\begin{tabular}{|c|c|c|c|}
\hline Parameter & $\begin{array}{c}\text { Control Country } \\
\text { (India) }\end{array}$ & $\begin{array}{c}\text { Treated Country } \\
\text { (China) }\end{array}$ & After \\
\hline & & Before & $6^{(i)}$ \\
\hline$g_{A}$ & 6 & 6 & 33 \\
\hline$\alpha$ & 33 & 33 & $3^{(i i)}$ \\
\hline$\delta$ & 3 & 3 & $3^{(i i i)}$ \\
\hline$r^{*}$ & 3 & 3 & $-1^{(i v)}$ \\
\hline$g_{L}$ & 2 & 2 & $66^{(v)}$ \\
\hline$\beta$ & 25 & 25 & \\
\hline
\end{tabular}

Table 2

(i) Consistent with Table 1 data post 1982.

(ii) Klenow and Rodriguez-Clare (1997, p. 76).

(iii) Accords with estimates in Holston et al. (2017).

(iv) This is a suggestive approximation to the one-child policy. As of this writing, China's birth rate has not risen in response to relaxation of the one-child policy.

(v) $\beta=25 \%$ corresponds to a savings rate of $20 \%$, while $\beta=66 \%$ corresponds to a savings rate of $40 \%$, an extreme value; see Imrohoroglu and Zhao (2018, Fig. 1, p. 36).

\subsection{Relative Growth in Capital and Labor}

India's population-control policies were broadly ineffective and India was exposed to the same globalization factors as China (especially in the mid-1990s). Accordingly, we postulate that India remained close to its steady-state path, and examine the difference in the capital growth rates between the two countries. In particular, equation (21) can be re-written as,

$$
\Delta g_{\bar{K}, t}=\frac{1}{1-\alpha} \ln \left[\frac{r^{*}+\delta-\psi(t-1, \hat{t})}{r^{*}+\delta-\psi(t, \hat{t})}\right]+\Delta g_{\bar{L}, t}+\Delta g_{\bar{A}, t}
$$

which relates the relative capital stock growth, China vs. India, to relative labor force and productivity growth rates. 
Consistent with the data in Table 1 , we assume $\Delta g_{\bar{A}, t}=0 .{ }^{22}$ Equation (22) then implies a direct positive connection between $\Delta g_{\bar{L}, t}$ and $\Delta g_{\bar{K}, t}$ and, in particular, a simultaneous drop of the $\Delta g_{\bar{L}, t}$ and $\Delta g_{\bar{K}, t}$ trajectories post 1982. Direct empirical evidence identifying this causal reversal, a drop in $\Delta g_{\bar{K}, t}$ caused by an exogenous drop in $\Delta g_{\bar{L}, t}$, is present in Figure 2. ${ }^{23}$ For the parameter choices in Table 2, Figure 4 portrays the indicated corresponding model-generated $\Delta g_{\bar{K}, t}$ and $\Delta g_{\bar{L}, t}$ trajectories, prior to and following a demographic intervention in period $10 .^{24}$ Figure 4 confirms that the implications of the theoretical model conform to the empirical observations detailed in Figure 2.
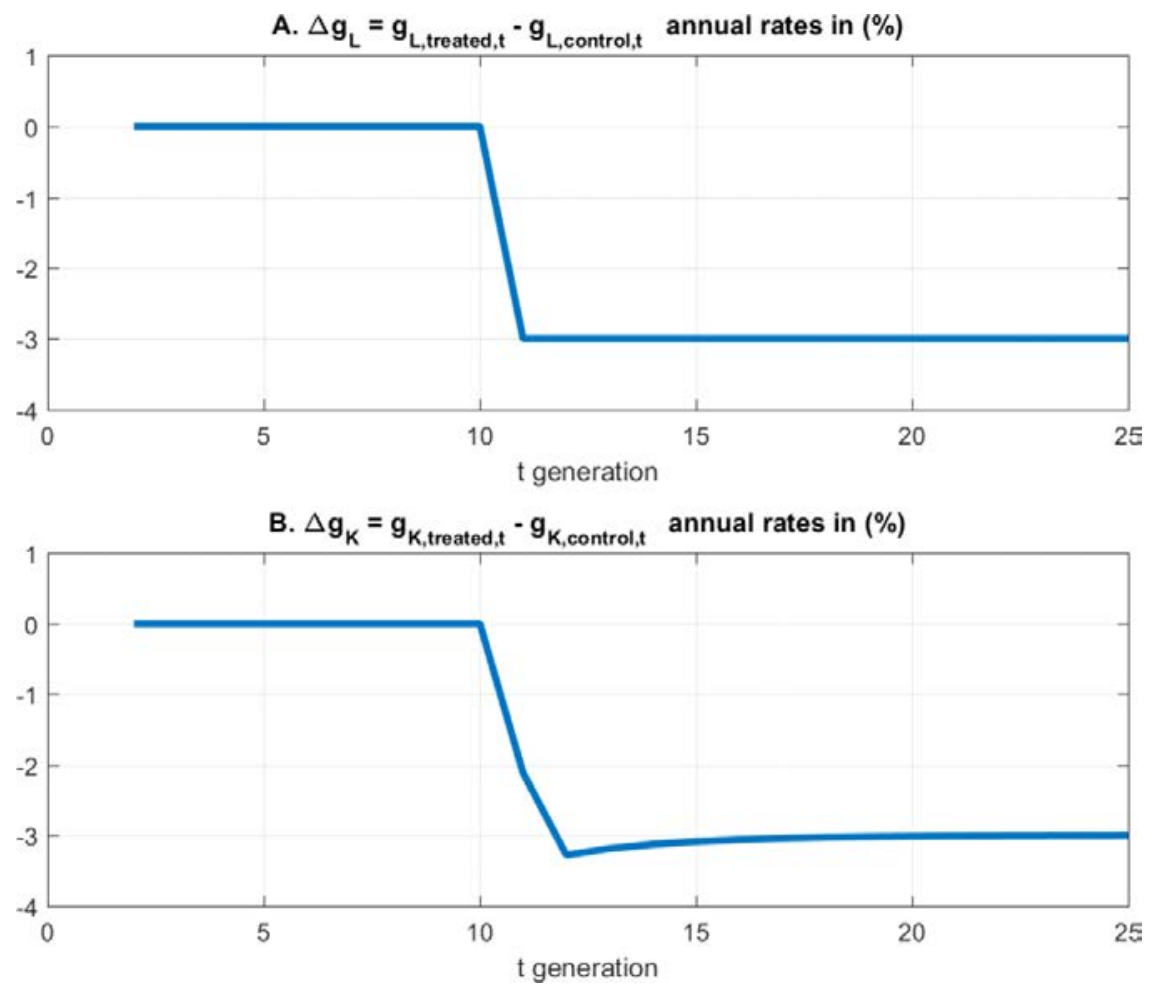

Figure 4 The effect of demographic intervention on the difference in the capital growth rates for the two economies around the time of the demographic intervention (treatment for one country only).

\footnotetext{
${ }^{22}$ As shown in Table 1, the productivity differences between China and India have been very small post 1982. This similarity allows us to focus on the comparative effects caused by the exogenous intervention in the population growth rate of China.

${ }^{23}$ The observed differences in magnitudes between $\Delta g_{\bar{K}, t}$ and $\Delta g_{\bar{L}, t}$ in Figure 2, can be theoretically attributed to the wedge dynamics in equation (22) and empirically to institutional, cultural or other latent factors.

${ }^{24}$ Note that the control country is initially identical to its treated counterpart even with reference to the level of labor productivity.
} 


\subsection{The impact of an exogenous demographic intervention on relative FDI dynamics}

Next, we focus on FDI, specifically the trajectories of capital inflows from the ROW. We assume that both countries initially have identical $\mathrm{K} / \mathrm{L}$ ratios and that their labor-productivity growth rates before and after the intervention are identical.

Figure 5 depicts model-generated differences between one country experiencing the exogenous, permanent, period-10 demographic intervention, and a country on its unaltered steady-state path. Panels A, C and E describe the consequences for the treated country. Panels B, D and F compare the treated response to the intervention with the corresponding quantities for the control country.
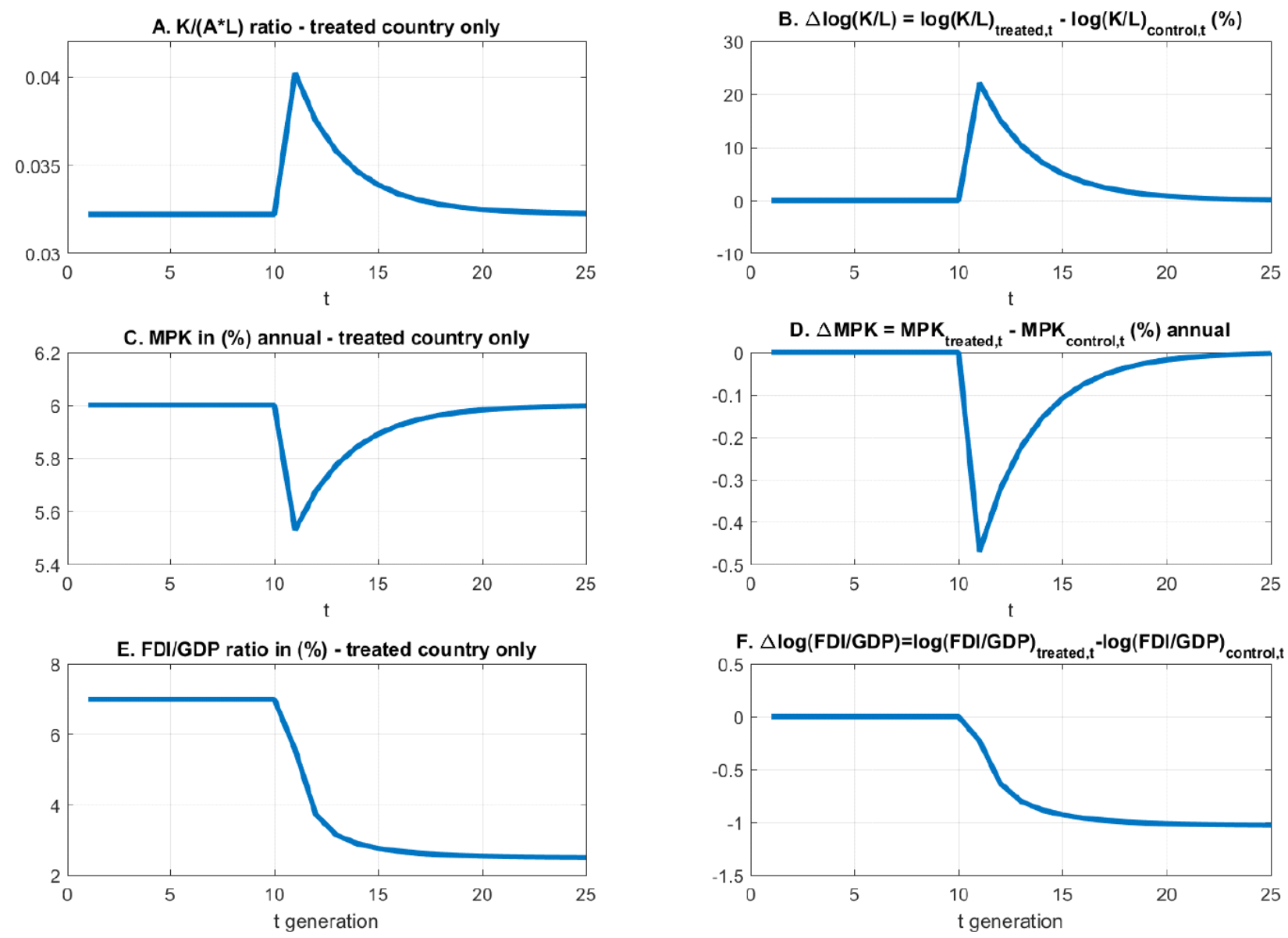

Figure 5 - Comparative time paths of K/L, MPK and FDI/GDP, for the two economies around the time of the demographic intervention (treatment for one country only). 
First consider Panels A and B. ${ }^{25}$ Following the demographic intervention, the $\mathrm{K} / \mathrm{L}$ ratio of the treated country spikes up (Panel A) before returning to its long run steady state value ${ }^{26}$. As a result, its $\mathrm{K} / \mathrm{L}$ ratio increases relative to the control country as captured in Panel B. ${ }^{27}$ After some generations, the effect disappears, with the K/L ratio in both countries becoming identical once again (Panel B) as required by their identical productivity growth rates. The K/L ratio effects are directly reflected in the corresponding MPK values: the abrupt increase in the treated country's K/L ratio has its counterpart in an absolute reduction in its MPK (Panel C), and a relative MPK reduction vis-a-vis the control country (Panel D). Following equation (19), adjustment costs are manifested first in a temporary drop in capital returns, driven by the capitalreturn friction, $\psi(t, \hat{t})=\eta \cdot(1-\chi)^{t-\hat{t}-1}$, that decays over time.

Panels $\mathrm{E}$ and $\mathrm{F}$ detail the consequences of the intervention for the FDI/GDP ratio of the treated country. As evident in equation (16), the steady state FDI/GDP ratio of country $i$ is positively related to its population growth rate $g_{\bar{L}, i}$. Accordingly, a reduction in the treated country's $g_{\bar{L}, i}$ reduces its FDI/GDP ratio, as seen in Panel E. Relative to the control country, its FDI/GDP ratio declines as well (Panel F). Although the $\mathrm{K} / \mathrm{L}$ ratio of the treated country eventually returns to its pre-intervention values (Panel A), the ownership composition of its capital stock has permanently changed in favor of proportionately less FDI.

To summarize: a permanent decline in the population growth rate of the treated country leads to, (i) a temporary, though prolonged, increase in the $\mathrm{K} / \mathrm{L}$ ratio above its steady state value, (ii) a temporary, though prolonged, decrease in the marginal product of capital below its steady state value, and (iii) a permanent reduction in its FDI/GDP ratio both absolutely and relative to its control counterpart. Note that Panel A of

\footnotetext{
${ }^{25}$ To assess the implications of Figure 5, the reader is reminded that if we consider two time series, $x_{t}$ and $z_{t}$, and plot $\log \left(x_{t}\right)-\log \left(z_{t}\right)$ over time, then an upward-sloping $\log \left(x_{t}\right)-\log \left(z_{t}\right)$ implies that $x_{t}$ grows faster than $z_{t}$.

${ }^{26}$ As stressed above, in equation (20), it is capital in efficiency units, $K /(A L)$, that is tied to the world interest rate, $r^{*}$. In order to better understand the dynamics of $\mathrm{K} / \mathrm{L}$ ratios we need to control for changes in the dynamics of labor productivity, $A$, which we plot in Panel A of Figure 5 as $K /(A L)$.

${ }^{27}$ Following the identification mentioned in the preceding paragraph, the K/L ratio in the treated country grew relative to its equivalent in the control country.
} 
Figure 5 depicts the time path of the normalized (by labor productivity, $A$ ) $\mathrm{K} / \mathrm{L}$ ratio.

The K/L ratio of both countries (except on the transition path for the treated country) thus continues to grow at the same growth rate as $A$.

\section{Model Generalizations}

Two related issues bear upon the generality of the results presented here, both of which could explain the observed increase in China's household savings rate during the policy intervention period. First, there is evidence that it may reflect an enhanced 'bequest motive' operating through parental desire to enhance a son's competitive advantage in the 'marriage market.' See Appendix A for the relevant literature. Second, life expectancy in China increased substantially during the period under study, though not dramatically more so than in India. The question addressed here is whether these exogenous phenomena alone are also powerful enough to replicate the results of the mechanism detailed in this paper. Within the present model context, the answer to this question is 'no'.

Both features may be incorporated into the present model framework via a straightforward preference generalization :

$$
U\left(c_{1, t}, c_{2, t}, B_{t+1}\right)=U\left(c_{1, t}\right)+\beta U\left(\frac{c_{2, t}}{N}\right)+\beta \kappa U\left(B_{t+1}\right),
$$

where we restrict preferences to display constant relative risk aversion. $B_{t+1}$ is the chosen bequest to the next generation and $\kappa$ is its relative importance vis-a-vis consumption utility. The term $N$ denotes the duration of an agent's post retirement period, with the aggregate amount saved for consumption in this period, $c_{2, t}$, assumed to be continuously and equally consumed at the average rate $\frac{c_{2, t}}{N}$. The solution to this problem, detailed in Online Appendix D is

$$
S_{t}=\frac{h\left(r^{*}, N, \kappa, \beta\right)}{1+h\left(r^{*}, N, \kappa, \beta\right)} w_{t}
$$

which is of the same form as (11). Furthermore,

$$
\frac{d h\left(r^{*}, N, \kappa, \beta\right)}{d N}>0 \text { and } \frac{d h\left(r^{*}, N, \kappa, \beta\right)}{d \kappa}>0 ; \text { i.e. }
$$

both an increase in the length of the retirement period and an increased emphasis on 
bequests act in the same way as an increase in the parameter $\beta$ to augment the household savings rate. In what follows, we therefore use equations (11) and (16) to compare the relative importance of the demographic mechanism in the paper with a simultaneous increase in the parameter $\beta$, the latter reflecting any one of several possible motivations. In all cases, we adopt the parameter values detailed in Table 2.

Consistent with these remarks, equation (16) reveals that a decrease in $g_{L}$ and an increase in $\beta$, work in the same direction. Accordingly, the increase in the saving rate and the one-child policy each will contribute to the observed decrease in the FDI/GDP ratio in China relative to India. Within our model, however, the one-child policy has a substantially greater effect on the FDI/GDP ratio than an increase in the savings rate. We confirm this assertion below.

\subsection{Comparative Steady State Calculations: a permanent drop in $g_{L}$ coupled with a permanent increase in $\beta$}

We compare the change in steady-state FDI/GDP ratio under three treatment scenarios: (1) a reduction in the population growth rate alone, (2) an increase in the savings rate alone and, (3), scenarios (1) and (2) jointly. Calculations based on equation (16) yield the following results:

(1) Scenario 1: A permanent decline in the treated country's $g_{L}$ alone from $2 \%$ to $-1 \%$ drops the steady-state FDI/GDP ratio from $8.2 \%$ to $5.72 \%$, a decline of about $30 \%$.

(2) Scenario 2: A permanent increase in the treated country's savings rate alone from $20 \%$ to $40 \%$ (corresponding to an increase in $\beta$ from $\beta=25 \%$ to $\beta=66 \%$ ) yields a drop in the steady-state FDI/GDP ratio from $8.2 \%$ to $6.27 \%$, a decline of about $23.5 \%$.

(3) Scenario 3: The effect of both these permanent changes simultaneously is a decline in the treated country's steady-state FDI/GDP ratio from $8.2 \%$ to $1.31 \%$, a drop of $84 \%$.

These calculations suggest that the one-child policy in China had a stronger effect on the observed drop in the FDI/GDP ratio than the increased savings rate. The combined effects (Scenario 3) capture most of the observed decline in the FDI/GDP ratio of China relative to that in India. Indeed, the relative drop in the FDI/GDP ratio implied by Figure 3 is $63 \%$. Since it is unlikely that a new steady state will be achieved in one generation, we evoked capital-adjustment frictions and modeled the increase in 
the $K / L$ ratio as occurring over multiple periods, which better captures the empirical implications of Figure 3.

\subsection{Dynamic Analysis: A permanent change in population growth with a temporary increase in the savings rate}

This section studies the case of a one-time increase in China's savings rate from $20 \%$ to $40 \%{ }^{28}$, coupled with a permanent drop in the population growth rate ${ }^{29}$. We assume that the increase applies only to the generation working during the period of one-child-policy implementation, returning to the original level of $20 \%$ thereafter. This anticipates that the retirement age will subsequently adjust (increase) for the first generation of children of the one-child policy, allowing the savings rate to return to its original level of $20 \%$. We therefore model the increase savings rate by a one-period increase in $\beta$.
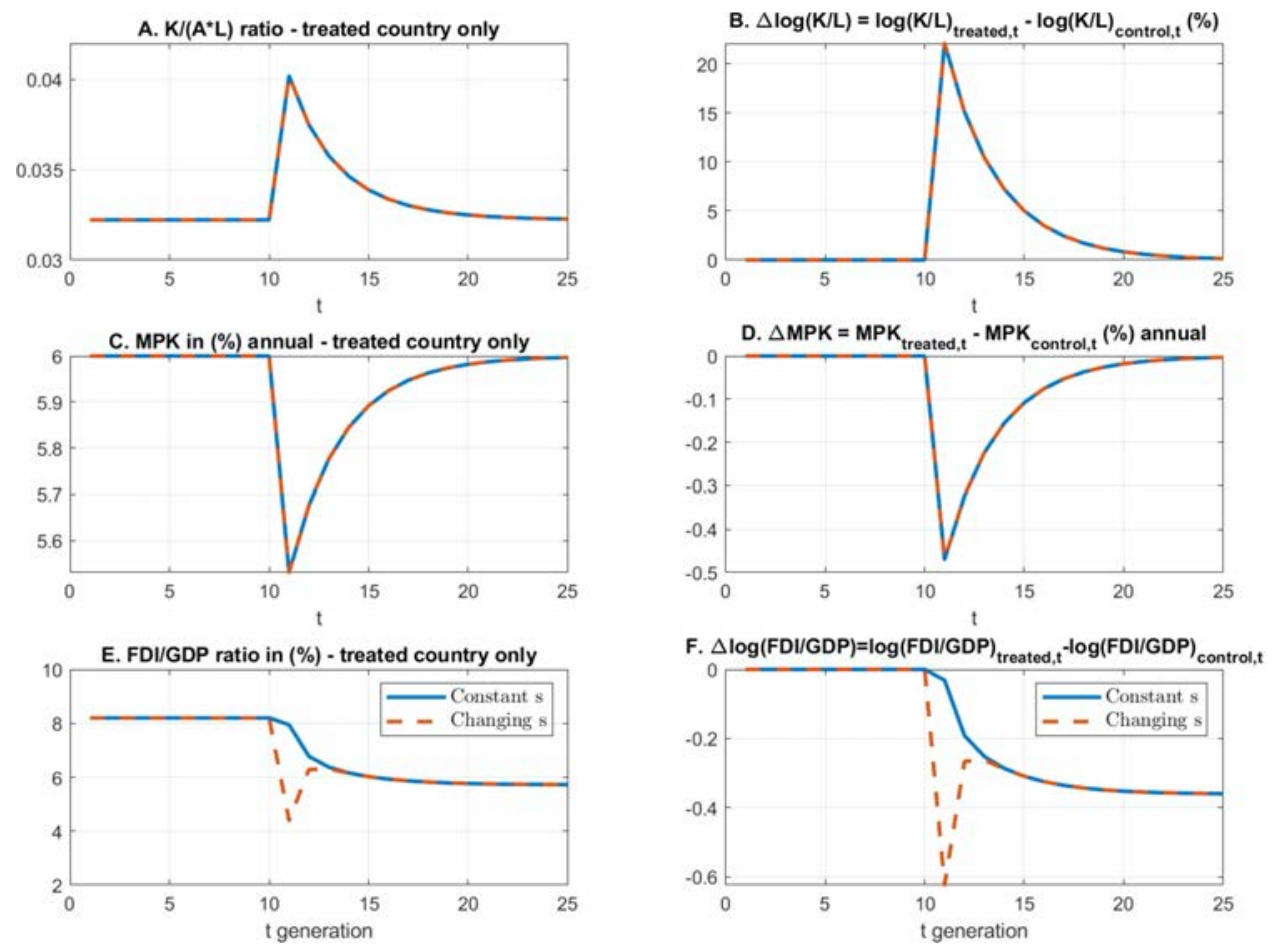

Figure 6 - Comparative time paths of FDI/GDP, for the two economies around the demographic intervention.

${ }^{28}$ This is the extreme case considered in Section 5.1.

${ }^{29}$ We are aware of China's recent transition to a two-child policy but retain this assumption because, following the trends in developed countries, we do not anticipate fertility to rise dramatically. 
The dashed lines in Figure 6 illustrate the results of this experiment while the continuous lines repeat the results of the experiment illustrated in Figure 5. Note that the effect on the relative $\mathrm{K} / \mathrm{L}$ ratio is greater than in the case of Section 5.1: namely a temporary increase in the savings rate implies a stronger temporary drop in the FDI/GDP ratio, one that better matches, quantitatively, the relative drop in the FDI/GDP ratio between China and India depicted by Figure 3. Once the increase in the savings rate disappears, however, the FDI/GDP ratio returns to the new steady state implied by the one-child policy only. ${ }^{30}$ Notice in Figure 6 Panel $\mathrm{F}$ the percentage drop in the FDI/GDP ratio after the one-child policy implementation is close to the observed $63 \%$ drop in relative FDI/GDP ratios between China and India seen in Figure 3.

We present further empirical evidence (Figure 7) in direct support of our mechanism by exploring FDI as a share of domestic investment (FDI/I ratio) in China and India for the period 1982-2014. Prior to 1992, the FDI/I ratio was low in China and negligible in India. While India's FDI/I ratio is generally increasing post 1992, the pattern for China is one of an initial dramatic increase, followed by a pronounced general decline.

FDI as share of Domestic Investment (\%)

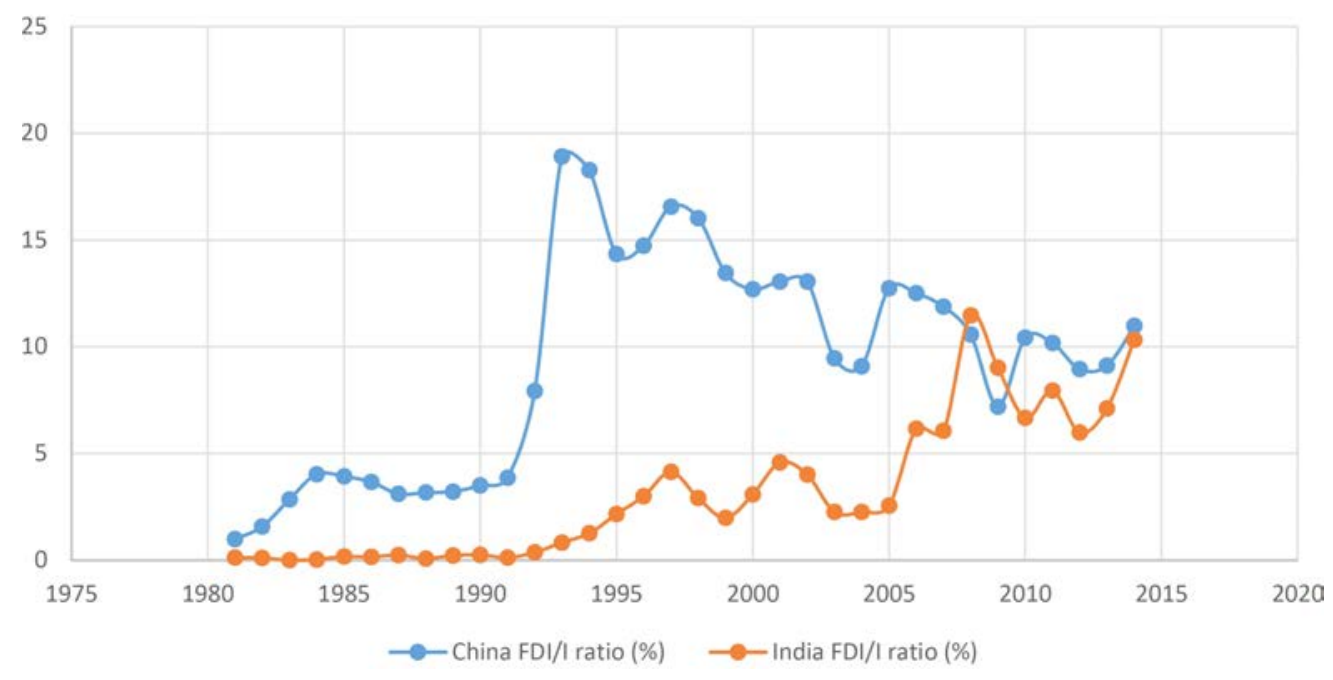

Figure 7 - FDI/I ratio in China and India

\footnotetext{
${ }^{30}$ We thank an anonymous referee for recommending this comparison to us.
} 
A major reason for the initial increase in China's FDI/I ratio is easily identified: in 1992 the Chinese government formally established "market economy reforms" in its constitution and began to strengthen private property rights by enforcing the "rule of law" for commercial transactions. As a structural landmark on China's transition to a market economy, these reforms made China a dramatically more attractive place for foreign investment. ${ }^{31}$

In summary, the theoretical implications of our model are: ${ }^{32}$

1. After a permanent drop in a country's population growth rate its FDI/GDP ratio will steadily decline to a new, permanently lower level (see Figure 5, Panel E, and equation (16)).

2. After a permanent drop in a country's population growth rate, its FDI/I ratio will similarly decline to a new, permanently lower level.

In Figure 7, China's FDI/I ratio does eventually decline, in accordance with the model's theoretical predictions ${ }^{33}$.

\section{Conclusion}

This paper is a contribution to the nascent literature focusing on the role of demographic changes in determining FDI flows. We examine the effects of crosscountry heterogeneity in population growth on relative FDI flows, a topic not previously addressed in the literature. In particular, we study the effects on FDI of an endogenous increases in a society's capital/labor ratio resulting from a population

${ }^{31}$ The second landmark year, 2001, marked China's joining the World Trade Organization (WTO).

${ }^{32}$ The simplifying assumptions of our model do not invalidate these theoretical predictions. For example, as a simple robustness check, we can use constant-relative-risk-aversion (CRRA) preferences and break the assumption of common labor productivities across domestic and FDI firms within a country. These two extensions compromise the closed-form results present here. Nevertheless, the numerical analysis of such an extended model supports the same qualitative conclusions as the theoretical predictions we list below.

${ }^{33}$ We attribute much of the observed gap in the series in Figure 7 broadly to other factors at play, and, in particular, to labor productivity growth. Specifically, Table 1 portrays a dramatic increase in China's productivity growth in the decades following 1982, while equation (16) implies a positive (steady-state) relationship between the FDI/GDP ratio and labor productivity growth. These facts suggest that China's enhanced productivity growth post 1982, per se, could lead to a higher FDI/I ratio, and that this effect may overwhelm the opposing force of lower population growth emphasized in the present paper. Accordingly, we hypothesize that the FDI/I pattern evident in Figure 7 is the result of the effects of higher productivity growth and lower population growth partially counterbalancing one another. 
decline. Our empirical setting is the mandatory one-child policy in China contrasted with India's comparatively laissez faire approach to population control.

This policy difference creates a natural experiment. We explore the resulting empirical evidence in the context of neoclassical model of FDI dynamics. The evidence and our analysis support the hypothesis that population dynamics may have a major impact on relative FDI flows. More generally, our results illustrate how demographic policies can have substantial effects on a countries economic activity. 


\section{REFERENCES}

Backus, D. K., T. Cooley, and E. Henriksen (2014): Demography and Low-Frequency Capital, Journal of International Economics, 92, Supplement 1, S94-S102.

Backus, D. K., P. J. Kehoe, and F. E. Kydland (1992): International Business Cycles, Journal of Political Economy, 100, 745-775.

Bollard, A., P. Klenow and G. Sharma (2013): India's Mysterious Manufacturing Miracle, Review of Economic Dynamics, 16, 59-85.

Cooley, T. and E. Henriksen (2018): The Demographic Deficit, Journal of Monetary Economics, 93, 45-62.

Diamond, P. A. (1965): National Debt in a Neoclassical Growth Model, American Economic Review, 55, 1126-1150.

Du, W., A. Tepper, and A. Verdelhan (2017): Deviations from Covered Interest Rate Parity, NBER Working Paper 23170.

Eggertsson, G., M. Lancaster, and L. Summers (2019): Aging, Output per Capita, and Secular Stagnation, American Economic Review - Insights, 1, 325-342.

Gerland, P. et al. (2014): World Population Stabilization Unlikely this Century. Science, 10 October 2014: 346 (6206), 234-237. doi:10.1126/science.1257469 - http://www.sciencemag.org/content/346/6206/234.full

Holmes, T. J., E. R. McGrattan and E. C. Prescott (2015): Quid Pro Quo: Technology Capital Transfers for Market Access in China, Review of Economic Studies, 82, 1154- 1193.

Holston, K., T. Laubach and J. C. Williams (2017): Measuring the Natural Rate of Interest: International Trends and Determinants, Journal of International Economics, 108, S59-S75.

Horioka, C. Y. (2014): Are Americans and Indians more altruistic than the Japanese and Chinese? Evidence from a New International Survey of Bequest Plans, Review of Economics of the Household, 12, 411-437.

Hsieh, C.-T., and P. Klenow (2009): Misallocation and Manufacturing TFP in China and India, Quarterly Journal of Economics, 124, 1403-1448. 
İmrohoroğlu, A. and K. Zhao (2018): The Chinese Saving Rate: Long-term Care Risks, Family Insurance, and Demographics, Journal of Monetary Economics, 96, $33-52$.

Klenow, P., Rodriguez-Clare, A. (1997): The Neoclassical Revival in Growth Economics: Has it Gone Too Far?, NBER Macroeconomics Annual, MIT Press, 73114.

Lucas, R. E. Jr (1990): Why Doesn't Capital Flow from Rich to Poor Countries?, American Economic Review, Papers and Proceedings, 80, 92-96.

McGrattan. E. R. and E. C. Prescott (2009): Openness, Technology Capital, and Development, Journal of Economic Theory, 144, 2454-2476.

McGrattan. E. R. and E. C. Prescott (2010): Technology Capital and the US Current Account, American Economic Review, 1493-1522.

Raftery, A.E., N. Li, H. Ševčíková, P. Gerland, and G.K. Heilig. (2012): Bayesian Probabilistic Population Projections for all Countries. Proceedings of the National Academy of Sciences 109 (35):13915-13921.doi:10.1073/pnas.1211452109 Statista (2020), data website https://www.statista.com/ 


\title{
Online Appendices
}

\section{for \\ Demographics and FDI: Lessons from China's One-Child Policy}

\author{
John Donaldson ${ }^{\mathrm{a}}$, Christos Koulovatianos ${ }^{\mathrm{b}}$, \\ Jian Li ${ }^{\mathrm{b}, \mathrm{c}}$ and Rajnish Mehrad,e,f
}

April 2021

${ }^{a}$ Columbia Business School, Columbia University

b Department of Economics, University of Luxembourg

c International Business School, Zhejiang Gongshang University

d Department of Economics, Arizona State University

e NBER

${ }^{\mathrm{f}}$ NCAER 


\section{Online Appendix A - Literature review}

\subsection{Literature related to China's high savings rate}

Curtis et al. (2015) and Choukhmane (2020) hypothesize that reduced fertility implies fewer children to support parents in their old age, thereby inducing parents to increase their own savings. Wei and Zhang (2011) explain the increased savings rate as a competitive response to the policy-induced sex ratio imbalance: families save more to increase the wealth of their sons in order to enhance their position in the competition for increasingly scarce spouses. Imrohoroglu and Zhao (2018) emphasize the long-term care insurance traditionally provided by families, and how the one-child policy has decreased the ability of families to provide it. Parents are thus forced to self-insure and do so by saving more. Other related work includes Chamon and Prasad (2010) and Yang et al. (2013). Finally, Zhang (2017) provides a comprehensive overview of the socio-economic effects of the one-child policy in China.

Another likely reason behind the documented increase in China's the savings rate is the remarkable improvement in life expectancy in China (to compare the progression of life expectancy indices between China and India, see https://data.worldbank.org/). Accordingly, the associated health care and medical costs have increased tremendously, all of which encourage Chinese households to save more. Moreover, in the past decades, the geographical mobility of young Chinese cohorts is much higher than the previous generation due to the drastic relaxation of the residential registration system (Hukou system). Hence, the monetary cost for supporting elder parents has also increased due to mobility-induced spatial separations, which also compels elderly parents to save more for retirement.

Regarding the extent of the change in the Chinese savings rate since 1980, there is some disagreement in the literature. Using the gross domestic savings to GDP ratio as a measure

according to the World Bank, the Chinese savings rate increased from 33.4\% in 1982 to 
$47.5 \%$ in 2014, a 14.1 percentage points increase. Choukhmane et al. (2020) used the Chinese Urban Household Survey (CEIC data) and showed an increase of 20 percentage points from $10 \%$ in 1980 to approximately 30\% in 2015. Imrohoroglu and Zhao (2018) document the savings rate in China as increasing from $20 \%$ to $40 \%$, an extreme view in the literature that we adopt for illustrative purposes.

\subsection{Literature related to China's high capital returns}

Bai et al. (2006) were the first to document the high capital returns in China (exceeding $20 \%$ post 1993) carefully. They conclude that China's high investment rate is consistent with the observed high returns. Nevertheless, mapping the documented high returns reported by Bai et al. (2006) to the aggregative concept of MPK under perfect foresight that we employ in this paper is not a straightforward task. Cochrane, in the discussion of Bai et al. (2006, p. 99), notes that the comparatively high return in China should be adjusted for differences in risk. Nordhaus and Cooper's discussion of Bai et al. (2006) emphasizes that a sudden conversion of land from agricultural to residential use is a process that can increase capital returns (capital gains) in ways that are not captured in standard equilibrium capital theory analysis. The discussion appears on pages 93-98, following Bai et al. (2006). Bai et al. (2006, Table 1 and Figure 2, pp. 72-75) also report a nearly 60\% decline in capital returns in China from 1993-2001. This dramatic decline cannot be fully attributed to a TFP-growth decline, possibly validating the comments by Nordhaus and Cooper in Bai et al. (2006, pp. 93-98). Part of this decline can be explained, however, by the anticipated rapid decline in China's population growth rate, as reported in Figures 1 and 2 of the present paper. Song et al. (2011) explore the seeming contradiction implicit in China's simultaneous high capital returns and high capital outflows. Their model rests on the internal reallocation of capital out of low growth firms that are large, externally financed, and whose capital needs are low. In 
contrast, high growth, high productivity firms are small and subject to capital constraints. They thus finance their rapidly increasing investments out of internally generated funds alone. As a result, the surplus capital from low growth firms migrates abroad, while the relative growth in the high productivity firms allows the high overall capital returns to be

observed. A more recent study also reporting high capital returns in China and focusing on the link between these returns and the housing boom in China, is Chen and Wen (2017). Nothing in the present model depends on the precise level of capital returns.

\section{REFERENCES}

Bai, C.-E., C.-T. Hsieh and Y. Qian (2006): The Return to Capital in China, Brookings Papers on Economic Activity, Vol. 2006(2), 61-88.

Chamon, M. D. and E. S. Prasad (2010): Why Are Saving Rates of Urban Households in China Rising?, American Economic Journal: Macroeconomics, 2, 93-130.

Chen, K. and Y. Wen (2017): The Great Housing Boom of China, American Economic Journal: Macroeconomics, 9(2), 73-114.

Choukhmane, T., N. Coeurdacier, and K. Jin (2020), The One-Child Policy and Household Saving, mimeo, London School of Economics.

Curtis, C. C., S. Lugauer and N. C. Mark (2015): Demographic Patterns and Household Saving in China, American Economic Journal: Macroeconomics, 7, 58-94.

İmrohoroğlu, A. and K. Zhao (2018): The Chinese Saving Rate: Long-term Care Risks, Family Insurance, and Demographics, Journal of Monetary Economics, 96, 33-52.

Song, Z., K. Storesletten and F. Zilibotti (2011): Growing Like China, American Economic Review, 101, 196-233.

Wei, S.-J. and X. Zhang (2011): The Competitive Saving Motive: Evidence from Rising Sex Ratios and Savings Rates in China, Journal of Political Economy, 119, 511-564.

Yang, D. T., J. Zhang and S. Zhou (2013), Why Are Saving Rates So High in China?, Chapter in NBER book "Capitalizing China", edited by Joseph Fan and Randall Morck, 249-278.

Zhang, J. (2017): The Evolution of China's One-Child Policy and Its Effects on Family Outcomes, Journal of Economic Perspectives, 31, 141-160. 


\section{Online Appendix B - Proof of production aggregation}

We omit time subscripts for simplicity. From equations (1), (2), and (3), we obtain,

$$
\bar{Y}_{i}=\bar{A}_{i}^{1-\alpha_{i}} K_{i}^{\alpha_{i}} L_{i}^{1-\alpha_{i}}\left[1+\left(\frac{F D I_{i}}{K_{i}}\right)^{\alpha_{i}}\left(\frac{L_{i}^{r}}{L_{i}}\right)^{1-\alpha_{i}}\right] .
$$

Assuming frictionless cross-country capital flows, condition (6) implies the equilibrium condition:

$$
r^{*}+\delta=M P K_{i, t}=M P K_{i, t}^{r}
$$

Combining equations (B.2), (2), and (3), we obtain,

$$
F D I_{i} \cdot L_{i}=K_{i} \cdot L_{i}^{r}
$$

Equation (B.1), combined with (B.3) and (4) becomes,

$$
\bar{Y}_{i}=\bar{A}_{i}^{1-\alpha_{i}} K_{i}^{\alpha_{i}} L_{i}^{-\alpha_{i}} \bar{L}_{i}
$$

Adding the term $K_{i} \cdot L_{i}$ to both sides of equation (B.3) leads to $\left(K_{i}+F D I_{i}\right) \cdot L_{i}=K_{i}$. $\left(L_{i}+L_{i}^{r}\right)$, which implies,

$$
\frac{\bar{K}_{i}}{\bar{L}_{i}}=\frac{K_{i}}{L_{i}},
$$

given (4), and given that $\bar{K}_{i}=K_{i}+F D I_{i}$. Combining (B.4) with (B.5) we obtain

$$
\bar{Y}_{i}=\bar{A}_{i}^{1-\alpha_{i}}\left(\frac{\bar{K}_{i}}{\bar{L}_{i}}\right)^{\alpha_{i}} \bar{L}_{i}
$$

which coincides with equation (12), proving the aggregation result. 


\section{Online Appendix C - Proof of equations (14), (15), and (16)}

Equation (13) implies $r^{*}+\delta=\alpha_{i} \bar{K}_{i, t}^{\alpha_{i}-1}\left(\bar{A}_{i, t} \bar{L}_{i, t}\right)^{1-\alpha_{i}}$, which gives,

$$
\bar{K}_{i, t}=\left(\frac{\alpha_{i}}{r^{*}+\delta}\right)^{\frac{1}{1-\alpha_{i}}} \bar{A}_{i, t} \bar{L}_{i, t} .
$$

Substituting (C.1) into (12) gives equation (14).

To prove (15), notice that (11) and (12) give,

$$
K_{i, t+1}=(1-\delta) K_{i, t}+\frac{\beta_{i}\left(1-\alpha_{i}\right)}{1+\beta_{i}} \bar{Y}_{i, t} .
$$

Substituting (C.2) into (14) implies,

$$
K_{i, t+1}=(1-\delta) K_{i, t}+\frac{\beta_{i}\left(1-\alpha_{i}\right)}{1+\beta_{i}}\left(\frac{\alpha_{i}}{r^{*}+\delta}\right)^{\frac{\alpha_{i}}{1-\alpha_{i}}} \bar{A}_{i, t} \bar{L}_{i, t} .
$$

Dividing both sides of equation (C.3) by $\bar{A}_{i, t} \bar{L}_{i, t}$, and considering constant exogenous growth rates for technology and population, $g_{\bar{A}, i}$ and $g_{\bar{L}, i}$, we obtain,

$$
e^{g_{\bar{A}, i}+g_{\bar{L}, i}} \frac{K_{i, t+1}}{\bar{A}_{i, t+1} \bar{L}_{i, t+1}}=(1-\delta) \frac{K_{i, t}}{\bar{A}_{i, t} \bar{L}_{i, t}}+\frac{\beta_{i}\left(1-\alpha_{i}\right)}{1+\beta_{i}}\left(\frac{\alpha_{i}}{r^{*}+\delta}\right)^{\frac{\alpha_{i}}{1-\alpha_{i}}} .
$$

After placing domestic capital in efficiency units, $K_{i, t} /\left(\bar{A}_{i, t} \bar{L}_{i, t}\right)$, on a zero-growth steadystate path, so that $K_{i, t}^{s s} /\left(\bar{A}_{i, t} \bar{L}_{i, t}\right)=K_{i, t+1}^{s s} /\left(\bar{A}_{i, t+1} \bar{L}_{i, t+1}\right)$, equation (C.4) implies,

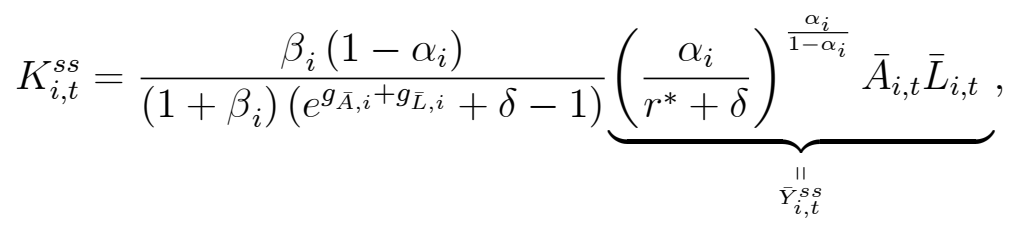

proving equation (15).

For proving equation (16), observe that equation (13) implies,

$$
\frac{\bar{K}_{i, t}^{s s}}{\bar{Y}_{i, t}^{s s}}=\frac{\alpha_{i}}{r^{*}+\delta} .
$$


Since $\bar{K}_{i, t}^{s s}=K_{i, t}^{s s}+F D I_{i, t}^{s s},($ C.6) gives,

$$
\frac{K_{i, t}^{s s}}{\bar{Y}_{i, t}^{s s}}+\frac{F D I_{i, t}^{s s}}{\bar{Y}_{i, t}^{s s}}=\frac{\alpha_{i}}{r^{*}+\delta} .
$$

Equation (C.5) combined with (14) implies,

$$
\frac{K_{i, t}^{s s}}{\bar{Y}_{i, t}^{s s}}=\frac{\beta_{i}\left(1-\alpha_{i}\right)}{\left(1+\beta_{i}\right)\left(e^{g_{\bar{A}, i}+g_{\bar{L}, i}}+\delta-1\right)} .
$$

Combining (C.7) and (C.8) proves equation (16). 


\section{Online Appendix D - Why longer duration of the post-retirement period and bequest motives can be translated into an increase in the discount factor $\beta$}

Consider a generalized version of our log-preferences, given by

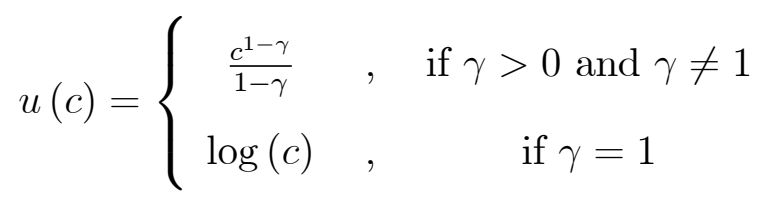

and consider that lifetime utility of a person in the young generation is,

$$
U\left(c_{1, t}, c_{2, t}\right)=u\left(c_{1, t}\right)+\beta u\left(\frac{c_{2, t}}{N_{t+1}}\right)+\beta \kappa u\left(B_{t+1}\right),
$$

where $\kappa>0, u(\cdot)$ is given by (D.1), $1 / N_{t+1}$ is a discount factor determining the duration of the post-retirement period, that may vary due to changes in life expectancy that are not accompanied by proportional changes to the retirement age, and $B_{t+1}$ is the bequest to the next generation. When $N_{t+1}>1$, the post-retirement period is longer, a scenario of an increase in life expectancy that is not followed by an increase in the retirement age. Regarding the introduction of a bequest motive, we assume that this motive is introduced only in period $t$, i.e., in period $t, \kappa>0$, therefore there are no inherited bequests.

Our goal is to show that, whenever $\kappa>0$, introduced for the first time in period $t$, and whenever $N_{t+1}>1$, with $\gamma>1$, the savings rate, $s_{t} / w_{t}$, will always increase, and it will be equivalent with our original model having a temporarily higher value for parameter $\beta$.

In our model,

$$
c_{1, t}=w_{t}-s_{t},
$$

while $c_{2, t}=\left(1+r_{t+1}\right) s_{t}$ (see equation, (8)). However, with the bequest motive, (8) becomes,

$$
c_{2, t}=\left(1+r_{t+1}\right) s_{t}-B_{t+1} .
$$


After substituting (D.3) and (D.4) into (D.2), we obtain,

$$
U\left(c_{1, t}, c_{2, t}, B_{t+1}\right)=u\left(w_{t}-s_{t}\right)+\beta u\left(\frac{\left(1+r_{t+1}\right) s_{t}-B_{t+1}}{N_{t+1}}\right)+\beta \kappa u\left(B_{t+1}\right)
$$

Taking the first order conditions only with respect to $B_{t+1}$ yields (after some algebra),

$$
B_{t+1}^{*}=\frac{\Delta}{1+\Delta}\left(1+r_{t+1}\right) s_{t}
$$

where,

$$
\Delta=\kappa^{\frac{1}{\gamma}} N_{t+1}^{\frac{1}{\gamma}-1}
$$

Substituting $B_{t+1}^{*}$ from (D.6) into the objective function given by (D.5), gives,

$$
\begin{gathered}
U\left(c_{1, t}, c_{2, t}, B_{t+1}^{*}\right)=u\left(w_{t}-s_{t}\right)+\beta u\left(\frac{\left(1+r_{t+1}\right) s_{t}-\frac{\Delta}{1+\Delta}\left(1+r_{t+1}\right) s_{t}}{N_{t+1}}\right)+ \\
+\beta \kappa u\left(\frac{\Delta}{1+\Delta}\left(1+r_{t+1}\right) s_{t}\right),
\end{gathered}
$$

which simplifies to,

$$
U\left(c_{1, t}, c_{2, t}, B_{t+1}^{*}\right)=u\left(w_{t}-s_{t}\right)+\hat{\beta}_{t+1} u\left(s_{t}\right)
$$

where

$$
\hat{\beta}_{t+1} \equiv\left(1+r_{t+1}\right)^{1-\gamma} N_{t+1}^{\gamma-1}\left(1+\kappa^{\frac{1}{\gamma}} N_{t+1}^{\frac{1}{\gamma}-1}\right) \beta
$$

Let $\hat{s}_{t}^{*}$ denote optimal savings, i.e.,

$$
\hat{s}_{t}^{*} \equiv \underset{s_{t}}{\arg \max } U\left(c_{1, t}, c_{2, t} B_{t+1}^{*}\right)=\underset{s_{t}}{\arg \max }\left[u\left(w_{t}-s_{t}\right)+\hat{\beta}_{t+1} u\left(s_{t}\right)\right]
$$

which gives the optimal savings rate, namely, now maximizing (D.7) with respect to $s_{t}$ alone, after some algebra we obtain,

$$
\frac{\hat{s}_{t}^{*}}{w_{t}}=\frac{\hat{\beta}_{t+1}^{\frac{1}{\gamma}}}{1+\hat{\beta}_{t+1}^{\frac{1}{\gamma}}}
$$


For a scenario where one generation experiences an increase in life expectancy that is not followed by an increase in the retirement age, $N_{t+1}$ becomes greater than 1 for generation $t$. Equation (D.9) implies that, if $\gamma>1, \hat{\beta}_{t+1}$ increases, as generation $t$ realizes that it must save more in order to smooth out its post-retirement consumption, which is discounted. In addition, introducing the bequest motive, i.e., switching the value of $\kappa$ from $\kappa=0$ to $\kappa>0$, increases both $\hat{\beta}_{t+1}$ and the savings rate.

Nevertheless, equation (D.9) implies that $\hat{\beta}_{t+1}$ is affected by changes in $r_{t+1}$ as well. However, equation (18) implies that any change in the savings rate (e.g., an increase in the savings rate because $N_{t+1}$ increased), does not affect $r_{t+1}$, which is equal to the world interest rate, $r^{*}$ plus the adjustment cost $\psi(t, \hat{t})$. Therefore, for the case of $\gamma>1$, any general-equilibrium effects on $\hat{\beta}_{t+1}$ and on the savings rate will be the same in periods that $N_{t+1}$ changes and in periods that $N_{t+1}$ remains equal to 1.

Since (D.9) implies that $\hat{\beta}_{t+1}=\beta$ whenever $\gamma=1$, for the case of $\gamma=1$ we assume that parameter $\beta$ increases (see Sections 3.5.1 and 4). 


\section{Appendix E - Data Descriptions and Sources}

\begin{tabular}{|c|c|c|c|c|}
\hline year & China FDI/GDPratio (\%) & India FDI/GDPratio (\%) & Ratio & Iog(ratio) \\
\hline 1981 & 0.155 & 0.027 & 5.822 & 0.765 \\
\hline 1982 & 0.239 & 0.022 & 10.731 & 1.031 \\
\hline 1983 & 0.430 & 0.002 & 255.079 & 2.407 \\
\hline 1984 & 0.661 & 0.006 & 111.110 & 2.046 \\
\hline 1985 & 0.824 & 0.032 & 25.571 & 1.408 \\
\hline 1986 & 0.710 & 0.028 & 25.256 & 1.402 \\
\hline 1987 & 0.613 & 0.043 & 14.218 & 1.153 \\
\hline 1988 & 0.707 & 0.016 & 44.807 & 1.651 \\
\hline 1989 & 0.751 & 0.043 & 17.615 & 1.246 \\
\hline 1990 & 0.709 & 0.048 & 14.783 & 1.170 \\
\hline 1991 & 0.800 & 0.022 & 35.780 & 1.554 \\
\hline 1992 & 1.750 & 0.070 & 24.988 & 1.398 \\
\hline 1993 & 3.930 & 0.146 & 26.934 & 1.430 \\
\hline 1994 & 4.198 & 0.246 & 17.046 & 1.232 \\
\hline 1995 & 3.832 & 0.476 & 8.044 & 0.905 \\
\hline 1996 & 4.074 & 0.544 & 7.489 & 0.874 \\
\hline 1997 & 4.402 & 0.801 & 5.495 & 0.740 \\
\hline 1998 & 4.251 & 0.555 & 7.655 & 0.884 \\
\hline 1999 & 3.450 & 0.431 & 7.997 & 0.903 \\
\hline 2000 & 3.321 & 0.637 & 5.216 & 0.717 \\
\hline 2001 & 3.744 & 0.974 & 3.845 & 0.585 \\
\hline 2002 & 3.781 & 0.934 & 4.048 & 0.607 \\
\hline 2003 & 3.033 & 0.561 & 5.407 & 0.733 \\
\hline 2004 & 3.092 & 0.660 & 4.687 & 0.671 \\
\hline 2005 & 4.240 & 0.783 & 5.418 & 0.734 \\
\hline 2006 & 4.290 & 1.978 & 2.168 & 0.336 \\
\hline 2007 & 4.404 & 2.070 & 2.127 & 0.328 \\
\hline 2008 & 4.322 & 3.518 & 1.228 & 0.089 \\
\hline 2009 & 3.234 & 2.952 & 1.095 & 0.040 \\
\hline 2010 & 4.914 & 2.209 & 2.224 & 0.347 \\
\hline 2011 & 4.811 & 1.816 & 1.853 & 0.268 \\
\hline 2012 & 4.178 & 2.300 & 0.362 \\
\hline 2013 & 4.290 & 2.157 & 0.334 \\
\hline 2014 & 5.132 & 1.814 & 0.259 \\
\hline & & & & \\
\hline
\end{tabular}

Table E.1 Data on FDI/GDP ratios 


\section{Foreign Direct Investment $^{1}$}

We use four different data sources to cross-verify the FDI inflows and outflows of China and India.

1. OECD: 1990-2013. Historic time series from OECD FDI statistics to end-2013 (http://www.oecd.org/daf/inv/investment-policy/fdi-statistics-according-tobmd3.htm).

2. National Accounts: 1982 - 2014. National Bureau of Statistics China (NBS-China) provides FDI outflow and inflow information (http://datE.stats.gov.cn/english/index.htm).

3. UNCTAD (United Nations Conference on Trade and Development): 1981-2013.The UNCTAD work program on FDI Statistics documents and analyzes global and regional trends in FDI.

4. DataStream: 1981-2016 (Quarterly). Thomson Reuters DataStream provides quarterly data on FDI inflows and outflows for China and India. ${ }^{2}$

Population Estimates and Forecasts: 1950-2100. United Nations: probabilistic population projections based on the world population prospects (the 2015 revision). ${ }^{3}$

GDP Series: 1990-2014, 2015-2018 (estimates). Work Bank, PPP adjusted at constant 2011 international USD.

Capital Stock -GDP ratio (K/Y ratio): PWT 9.0 (The Penn World Table).

FDI data come from four sources: (a) National Accounts, (b) OECD, (c) Datastream, and (d) UNCTAD. These sources cover different years, so we specify which we use in each context and document the correlation among these data sources. National account data for India is downloaded from the RBI website (https://rbi.org.in/Scripts/SDDSView.aspx) and it is identical to the data provided by OECD. So, we only report the OECD source.

\footnotetext{
${ }^{1}$ All FDI statistics from different sources use 2010 USD as the base dollar value.

2 The quarterly data sources are composed by Oxford Economics (http://www.oxfordeconomics.com/).

${ }^{3}$ United Nations (2015). Probabilistic Population Projections based on the World Population Prospects: The 2015 Revision.

Population Division, DESA. http://esE.un.org/unpd/ppp/.
} 


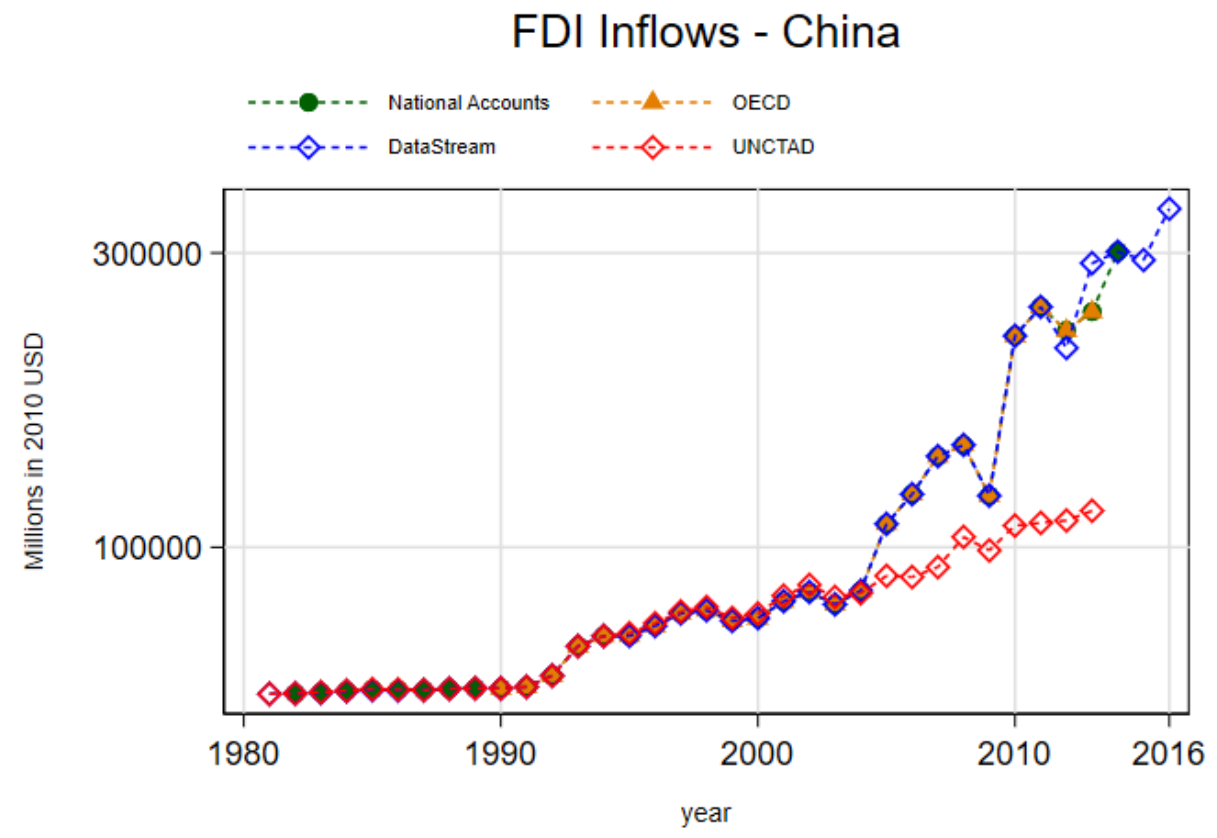

Figure E.1

The sources used in the paper are National-accounts data for the period 1982-2014 and Datastream data for years 2015-2016. National-accounts data and Datastream data overlap over the period 1982-2014 with a correlation coefficient of $99.79 \%$.

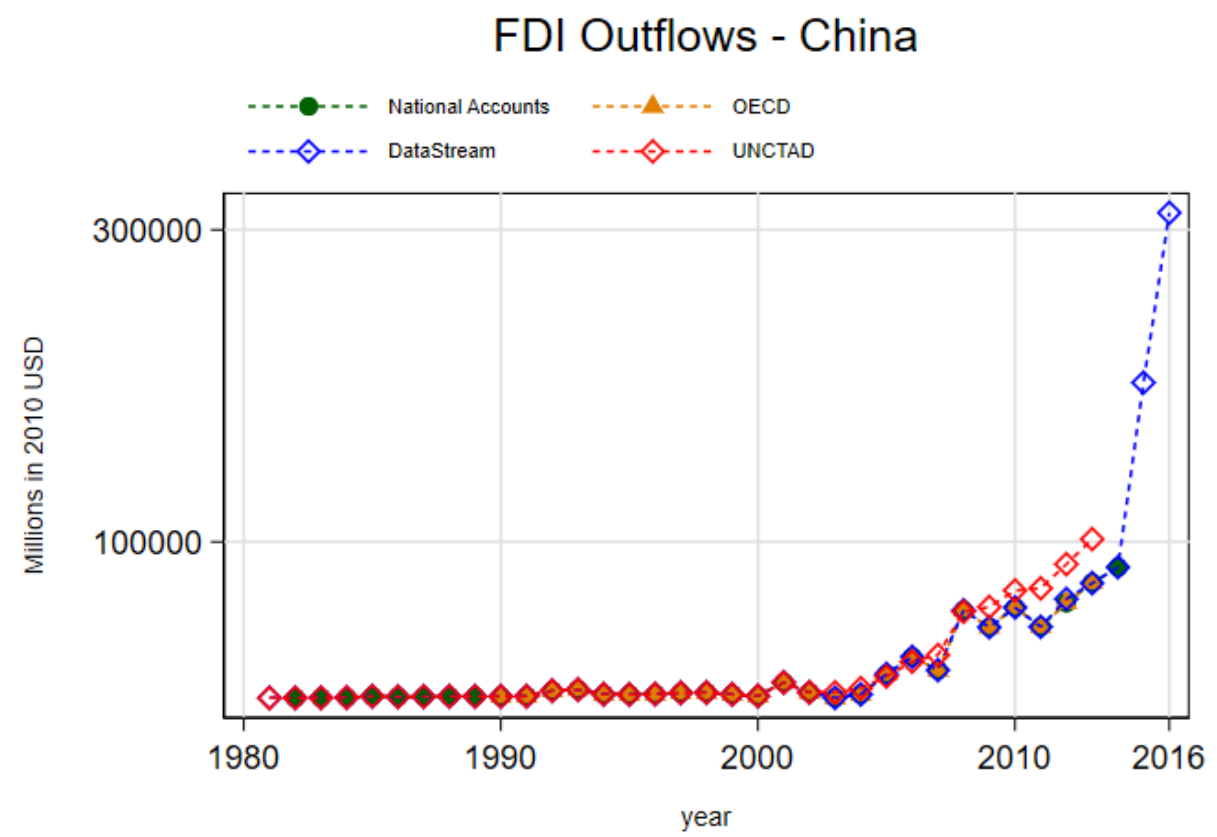

Figure E.2

The sources used in the paper are National-accounts data for the period 1982-2014 and Datastream data for years 2015-2016. National-accounts data and Datastream data overlap over the period 1982-2014 with a correlation coefficient $99.99 \%$. 


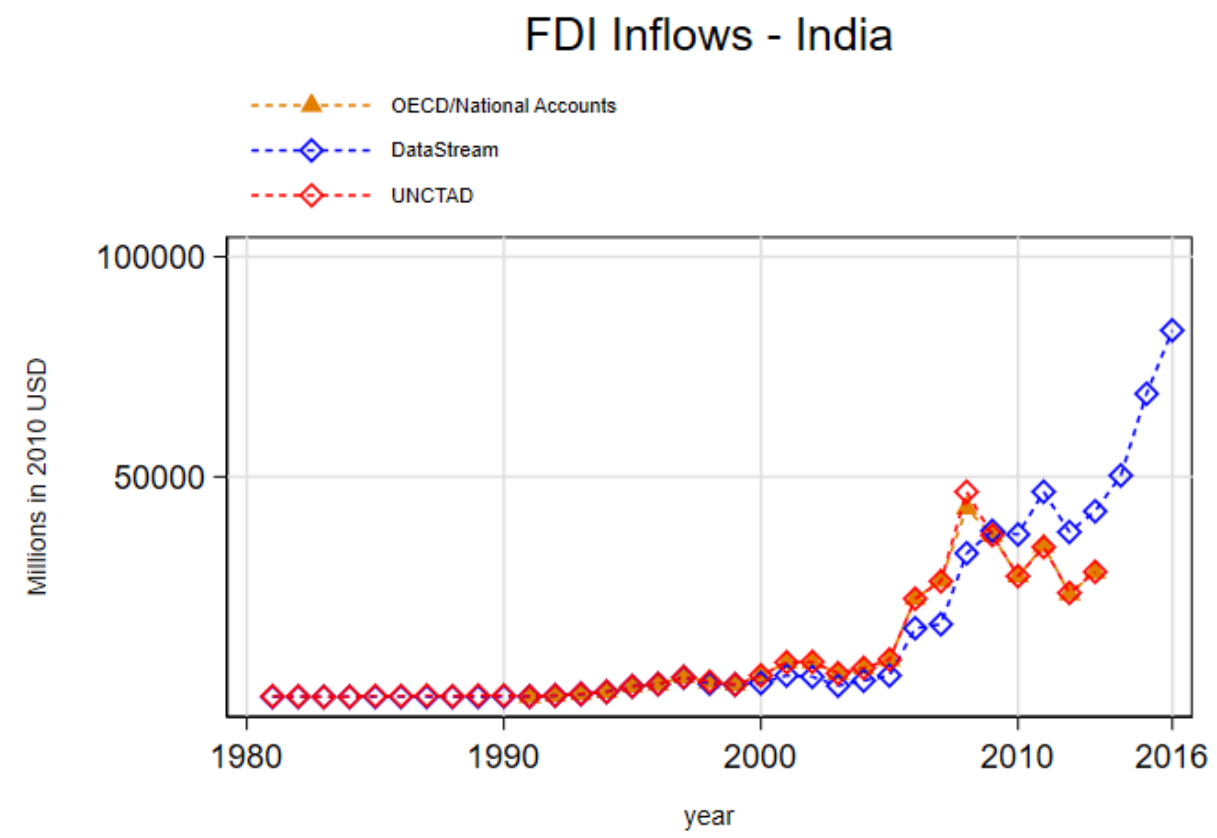

Figure E.3

The sources used in the paper are UNCTAD data for the period 1981-2013 and Datastream data for years 2014-2016. UNCTAD data and Datastream data overlap over the period 1981-2013 with a correlation coefficient of $92.56 \%$. The reason we have chosen UNCTAD data for the period 1981-2013 is because, (a) for the period between 1981 and 1989 Datastream reports zero values (but not missing values), and $\quad$ (b) the two data sources overlap over the period 1991-2013 with a correlation coefficient of $99.87 \%$.

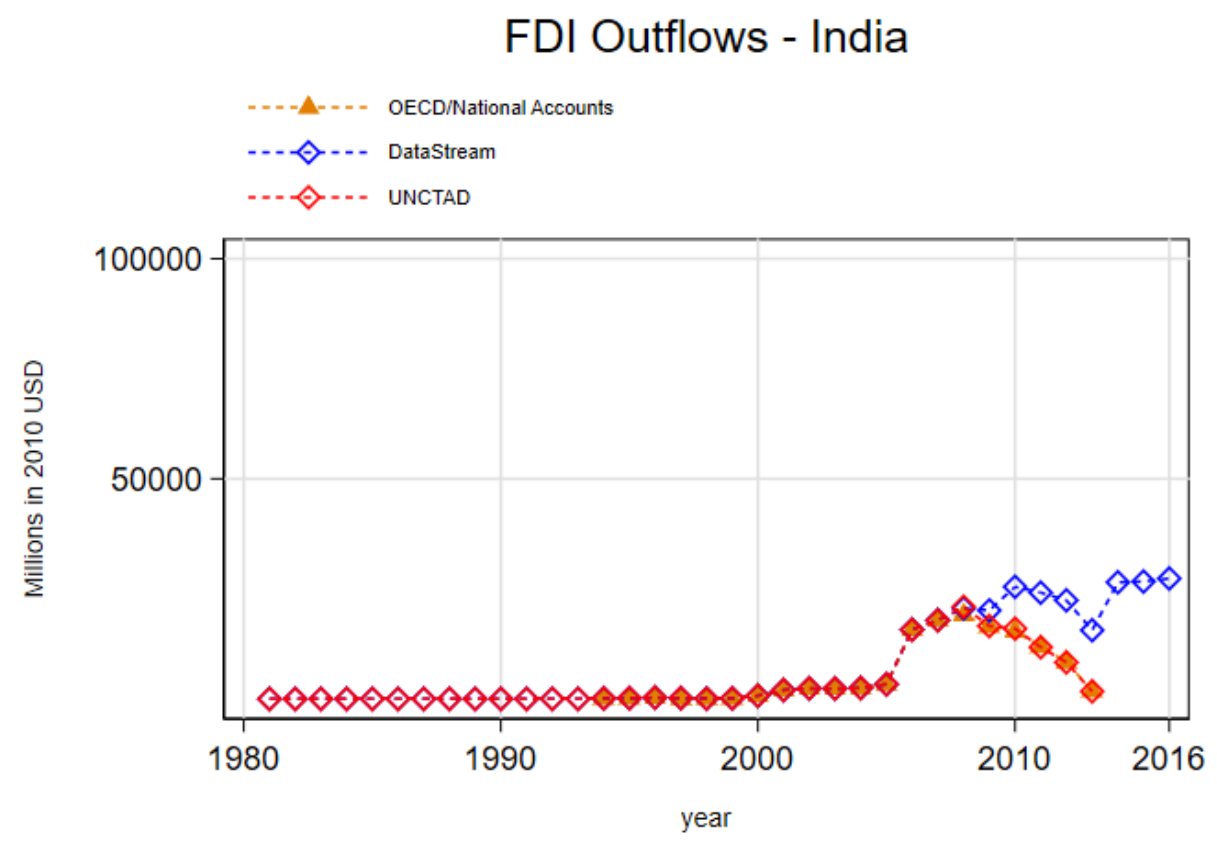

Figure E.4

The sources used in the paper are UNCTAD data for the period 1981-2013 and Datastream data for years 2014-2016. UNCTAD data and Datastream data overlap over the period 1981-2013 with a correlation coefficient of 89.32\%. The reason we have chosen UNCTAD data for the period 1981-2013 is because, (a) for the period between 1981 and 1993 Datastream reports zero values (but not missing values), and $\quad$ (b) the two data sources overlap over the period 1994-2013 with a correlation coefficient of 99.86\%. 


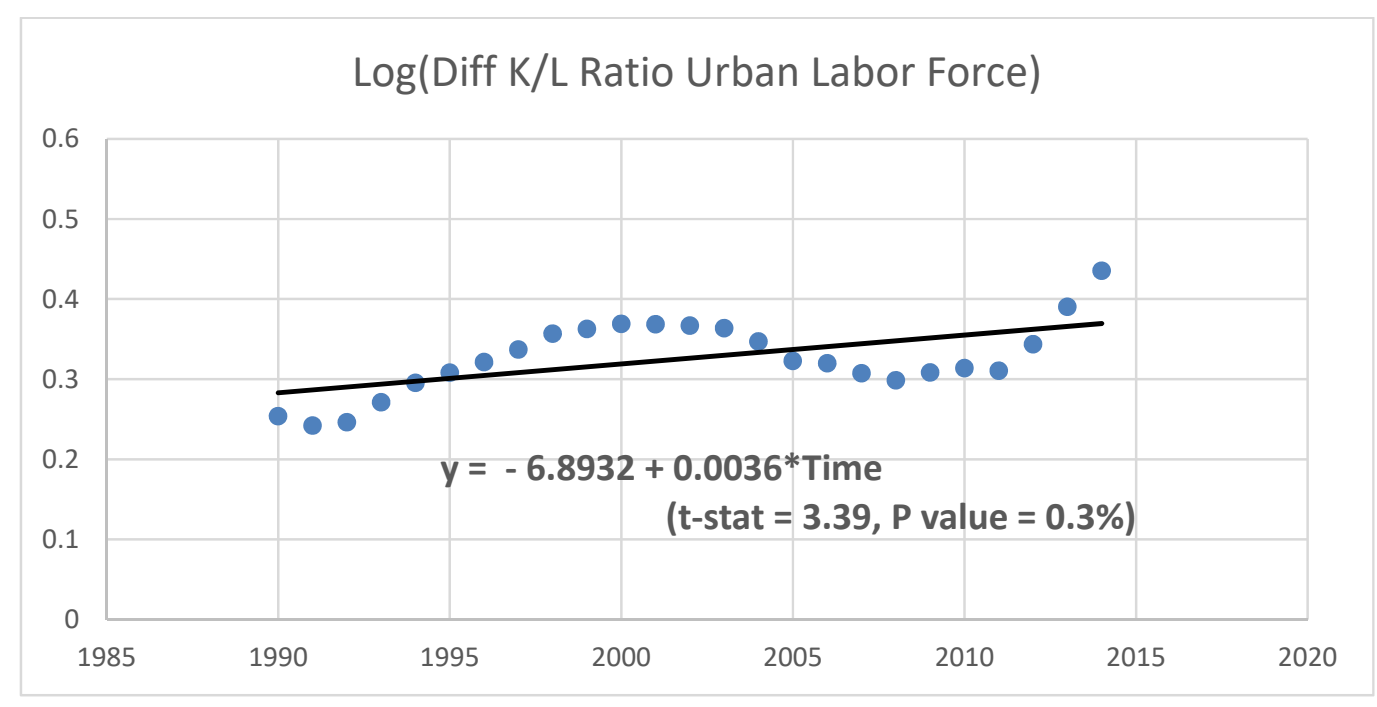

Figure E.5

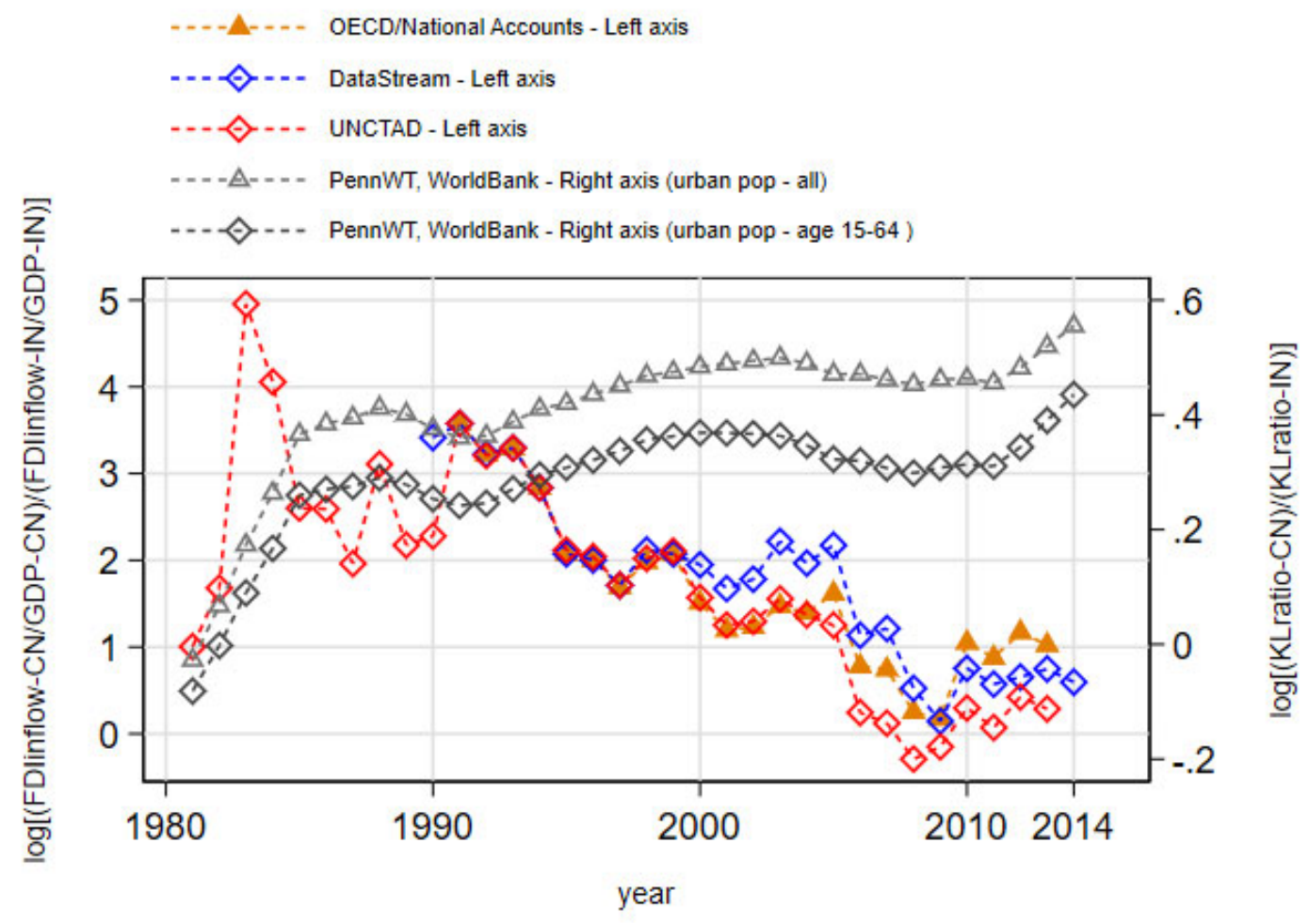

Figure E.6

To address the concern that large-scale internal migration in China would decrease the capital-labor ratio instead of increasing it, we use the urban population, restricted to ages 15-64 and perform a robustness check. Figure E.5 shows that the linear time trend coefficient (of the $\log \mathrm{K} / \mathrm{L}$ ratio of China over the K/L ratio of India) is positive and statistically significant (not equal to 0 with p-value at $0.3 \%$ ). In Figure E.6 where we plot a similar data series as Figure 5 (in the paper) using this restricted sample, all the quantitative results remain. 
The first two columns of Table E.2 provide the data appearing in Figure E.6 (without the logarithmic conversion of ratios). The last two columns of Table E.2 are the two new urban (working) population series appearing in Figure E.6.

\begin{tabular}{|c|c|c|c|c|}
\hline year & Ratio_FDIY & Ratio_FullPop & Ratio_PopUrban & Ratio_PopUrbanWorking \\
\hline 1990 & 30.45 & 0.96 & 1.46 & 1.29 \\
\hline 1991 & 35.73 & 0.99 & 1.43 & 1.27 \\
\hline 1992 & 25.08 & 1.02 & 1.44 & 1.28 \\
\hline 1993 & 26.94 & 1.07 & 1.47 & 1.31 \\
\hline 1994 & 17.04 & 1.13 & 1.51 & 1.34 \\
\hline 1995 & 7.96 & 1.17 & 1.52 & 1.36 \\
\hline 1996 & 7.42 & 1.22 & 1.55 & 1.38 \\
\hline 1997 & 5.54 & 1.27 & 1.57 & 1.40 \\
\hline 1998 & 8.32 & 1.32 & 1.60 & 1.43 \\
\hline 1999 & 7.95 & 1.36 & 1.61 & 1.44 \\
\hline 2000 & 7.02 & 1.41 & 1.62 & 1.45 \\
\hline 2001 & 5.33 & 1.50 & 1.63 & 1.45 \\
\hline 2002 & 5.94 & 1.57 & 1.64 & 1.44 \\
\hline 2003 & 9.19 & 1.66 & 1.65 & 1.44 \\
\hline 2004 & 7.14 & 1.73 & 1.63 & 1.41 \\
\hline 2005 & 8.79 & 1.72 & 1.60 & 1.38 \\
\hline 2006 & 3.11 & 1.72 & 1.60 & 1.38 \\
\hline 2007 & 3.36 & 1.71 & 1.59 & 1.36 \\
\hline 2008 & 1.69 & 1.68 & 1.57 & 1.35 \\
\hline 2009 & 1.16 & 1.70 & 1.59 & 1.36 \\
\hline 2010 & 2.12 & 1.72 & 1.59 & 1.37 \\
\hline 2011 & 1.77 & 1.72 & 1.58 & 1.36 \\
\hline 2012 & 1.92 & 1.77 & 1.62 & 1.41 \\
\hline 2013 & 2.11 & 1.87 & 1.68 & 1.48 \\
\hline 2014 & 1.81 & 1.97 & 1.74 & 1.55 \\
\hline & & & & \\
\hline
\end{tabular}

Table E.2 